\title{
Estudo de caso da análise de interferências entre as disciplinas de um edifício com projetos convencionais (re) modelados em BIM
}

\section{Case study of analysis of interferences between the discipline of a building with conventional designs (re) modeling in BIM}

Hygor de Castro Mesquita ${ }^{1}$, Raphael Canedo Eduardo ${ }^{1}$, Karen Campos Rodrigues ${ }^{1}$, Heber Martins de Paula ${ }^{1}$

\footnotetext{
${ }^{1}$ Prédio das Engenharias - Bloco O - FENG/UFG-RC, CEP: 75704-020, Catalão, GO, Brasil. e-mail: hygorcastro@hotmail.com, raphaeleduardo42@gmail.com, karencamposrodrigues@ hotmail.com, heberdepaula@ufg.br
}

\section{RESUMO}

A Modelagem da Informação da Construção ou Building Information Modeling (BIM) prevê a criação de um modelo paramétrico digital. $\mathrm{O}$ banco de dados criado possibilita a extração de informações concisas em todas as etapas de desenvolvimento do empreendimento. Esse conceito vai além do dimensionamento tridimensional e agrega conceitos de integração de equipes, análise de interferências, compatibilização e multidimensionalidade ao ato de projetar. O objetivo deste artigo é demonstrar, por meio da realização de um estudo de caso, a utilização da plataforma BIM para realizar a modelagem e análise de interferências dos projetos arquitetônico, estrutural e hidrossanitário de um edifício residencial multifamiliar. Para isto foi feita uma modelagem tridimensional a partir de projetos, em prancha 2D e digitais, que foram disponibilizados pelos engenheiros responsáveis pelo empreendimento, após a sua construção. Foram modelados no Revit ${ }^{\circledR}$ primeiramente o projeto arquitetônico, seguido pelo hidrossanitário e por último o estrutural. Os modelos tridimensionais foram então confrontados, no Navisworks ${ }^{\circledR}$. Como resultado foi possível, pela criação do modelo digital, a quantificação das interposições existentes na interface estrutural/hidrossanitário. Desta forma, após a execução análise, foi possível verificar quais interferências poderiam ter sido resolvidas já na mesa de projeto, evitando assim eventuais problemas na execução. Verificou-se na prática a interoperabilidade de softwares prevista pela plataforma BIM e a extração de informações do banco de dados gerado pela modelagem. Concluindo, assim, o possível benefício da aplicação da mesma tanto na fase dos projetos quanto no momento da execução.

Palavras-chave: BIM, Análise de Interferências, Gerenciamento de Projeto, Compatibilização.

\section{ABSTRACT}

Building Information Modeling (BIM) provides for the creation of a digital parametric model. The database created enables the extraction of concise information at all stages of the development of the enterprise. This concept goes beyond three-dimensional modeling and aggregates concepts of team integration, interference analysis, compatibilization and multi-dimensionality to the designing act. The objective of this article is to demonstrate, using a case study, the use of the BIM platform for the modeling and analysis of the interferences of the projects architectural, structural and hydrosanitary. For this, a three-dimensional modeling was done from projects, in 2D and digital boards, that were made available by the engineers responsible for the project, after its construction. The architectural design was first modeled in Revit ${ }^{\circledR}$, followed by the hydrosanitary and finally the structural one. The three-dimensional models were then confronted in Navisworks ${ }^{\circledR}$. As a result, it was possible, through the creation of the digital model, to quantify the existing interpositions at the structural/hydrosanitary interface. In this way, after the execution of the analysis, it was possible to verify which interferences could have been solved already in the design phase, thus avoiding eventual problems in the execution. The interoperability of software provided by the BIM platform and the extraction of information from the database generated by the modeling were verified in practice. This concludes the possible 
benefit of applying it both at the project stage and at the time of implementation.

Keywords: BIM, Interference Analysis, Project Management, Compatibility.

\section{INTRODUÇÃO}

Segundo CHIEN et al. [1] "BIM é uma tecnologia em desenvolvimento no qual os modelos de informações digitais são empregados em um espaço virtual para alcançar alta qualidade, construção eficiente e gerenciamento por todo o ciclo de vida de uma instalação".

De acordo com CAMPESTRINI [2] "Os primeiros usos do BIM têm se dado no mercado como uma ferramenta para compatibilização espacial do projeto". Sendo este mais utilizado na indústria de Arquitetura, Engenharia e Construção (AEC) tanto na fase de concepção do projeto, quanto nos estágios construtivos e de manutenção da vida útil das edificações.

Conforme $\mathrm{OH}$ et al.[3] , a medida que projetos de construção se tornam maiores e mais complicados, a quantidade de informação requerida aumenta consideravelmente. Diante de tal fato, podem surgir problemas relativos a interferências entre os diferentes projetos da construção, tornando necessária a realização de estudos de compatibilização dos mesmos. Em estudo realizado por LINDEROTH[4], foi observado que a compatibilização de projetos é a principal vantagem apreciada no início da adoção do BIM nas empresas, seguida por outras vantagens relativas ao estágio de produção. WON et al. [5] observou que o uso do BIM para encontrar e solucionar erros de desenho leva a redução de desperdícios e retrabalhos no canteiro de obras.

MARIANI et al. [6] observaram em estudo de caso de um edifício residencial dos impactos do BIM que a realização de análise de interferências ocasiona considerável redução no atraso da obra. LI et al. [7] afirma que a ferramenta de visualização das etapas de construção auxilia os responsáveis pelo planejamento dos projetos a identificar conflitos e na busca de alternativas que apresentem a melhor relação custobenefício e economia de tempo.

A utilização do BIM se torna justificável por criar um modelo digital que permite o trabalho simultâneo de diferentes equipes no projeto utilizando o mesmo arquivo como referência. Dessa forma, é possível integrar os diversos sistemas ou no caso disciplinas ${ }^{1}$ (elétrico, água, esgoto e pluvial, por exemplo) em um único modelo. Podendo ser identificadas incompatibilidades, evitando problemas futuros, além de gerar economia no processo de produção, uma vez que é possível ser feita uma real compatibilização do projeto.

Dessa forma, EASTMAN et al [8] observaram que a modernização na engenharia proveniente do BIM possibilitará a integração de equipes usufruindo da interoperabilidade de softwares, compatibilização de projeto, além da extração transparente de dados reais da obra, permitindo ainda que o projeto seja atualizado automaticamente quando houverem alterações no mesmo.

O objetivo deste trabalho é demonstrar, por meio da realização de um estudo de caso, a utilização da plataforma BIM para a modelagem e análise de interferências dos projetos arquitetônico, estrutural e hidrossanitário de um edifício residencial multifamiliar.

\section{MATERIAIS E MÉTODOS}

A pesquisa foi desenvolvida com base em um estudo de caso da modelagem em BIM de um projeto já executado e modelado em 2D que, segundo GIL[9], esta é uma modalidade de pesquisa que permite o amplo e detalhado conhecimento de um objeto após profundo estudo.

Foram modelados os projetos arquitetônico, estrutural e hidrossanitário, elaborados por MELO [10], CUNHA [11] e ROCHA [12], respectivamente. Foi utilizado ainda o projeto de paginação e detalhamento elaborado por BRAGA [13]. A modelagem tridimensional dos projetos foi procedida no Revit ${ }^{\circledR}$ 2017. O banco de dados foi concebido da mesma maneira como estavam descritos os elementos nos projetos. Foram utilizados como referência, para execução dos elementos tridimensionais, os arquivos fornecidos pela própria empresa (digital e impresso).

O projeto consta de um edifício multifamiliar contendo a garagem no pavimento térreo e três pavimentos tipo com seis apartamentos por andar e um dormitório por apartamento. Cada apartamento possui $44 \mathrm{~m}^{2}$. A área total construída do edifício é de $1362,38 \mathrm{~m}^{2}$. O fluxograma da metodologia está apresentado na Figura 1 .

\footnotetext{
${ }^{1} \mathrm{O}$ termo disciplinas é utilizado para se referir aos projetos que compõem um modelo de determinado edifício, com semântica diferente á de disciplinas de cursos acadêmicos.
} 


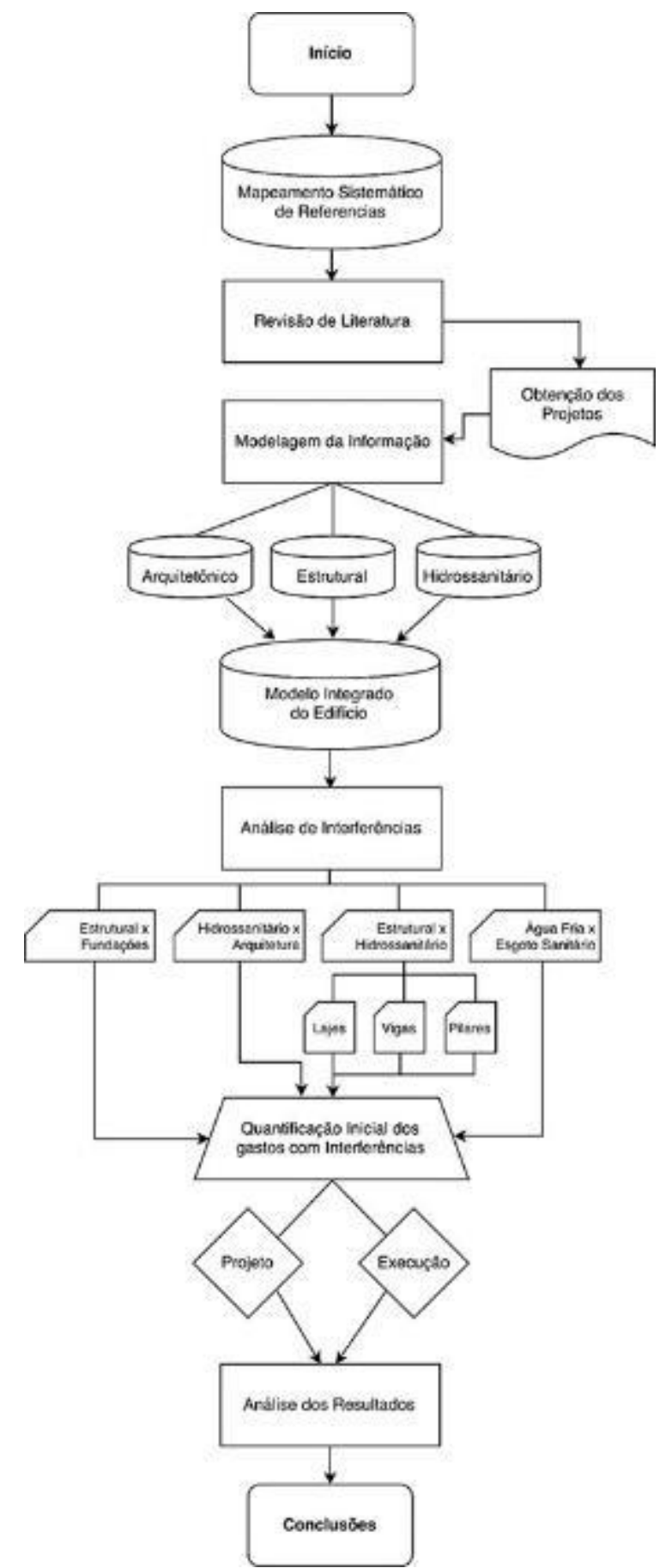

Figura 1: Fluxograma da metodologia de pesquisa

\subsection{Arquitetura}

A modelagem da edificação antes citada foi procedida no Revit® 2017. Apesar da utilização de um software específico, o procedimento efetuado transcende a um aplicativo propriamente dito, podendo ser efetuado em qualquer solução da Plataforma BIM. Foram utilizados como referência, para a execução dos elementos tridimensionais, os arquivos fornecidos pela própria empresa executora (digital e impresso). Cabe ressaltar que banco de dados foi concebido da mesma maneira como estavam descritos os elementos nos projetos. Foram adicionadas a maior quantidade de informações (detalhes) possíveis.

A primeira etapa foi o lançamento do projeto arquitetônico. Tal ordem se justifica uma vez que as referências da arquitetura são utilizadas para o posicionamento inicial da disciplina de MEP (Sistemas Prediais), neste caso o Hidrossanitário.

Após a análise do arquivo *.DWG referente à arquitetura fornecido pelo escritório, foram levantados os grupos de elementos, aqui chamados famílias, que compõem o projeto. Tais elementos foram importa- 
dos/desenvolvidos com base em modelos previamente disponíveis no programa.

O desenvolvimento das famílias não é perdido entre a finalização de um empreendimento e início de outro. As informações são armazenadas em um arquivo base, denominado "template", que fornece as diretrizes iniciais de concepção. Já existia no "template", próprio dos autores, a inclusão de algumas famílias. Tais como: esquadrias, elementos de piso básicos, paredes básicas, forros e telhados básicos, bem como elementos de detalhamento e impressão. Foram então organizadas as famílias para que estas atendessem as necessidades do projeto.

As famílias de Janelas importadas para utilização são mostradas na Figura 2. Na sequência foram definidas as famílias de Portas a serem utilizados. A Figura 3 mostra a vista frontal dos modelos de portas utilizados.

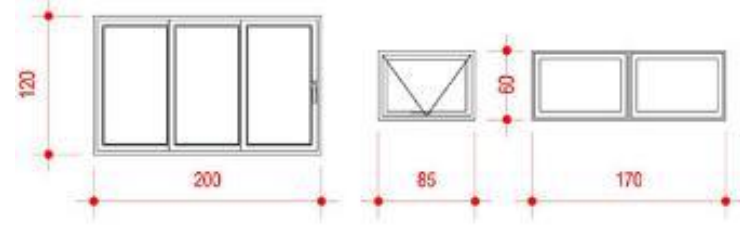

Figura 2: Famílias de janelas

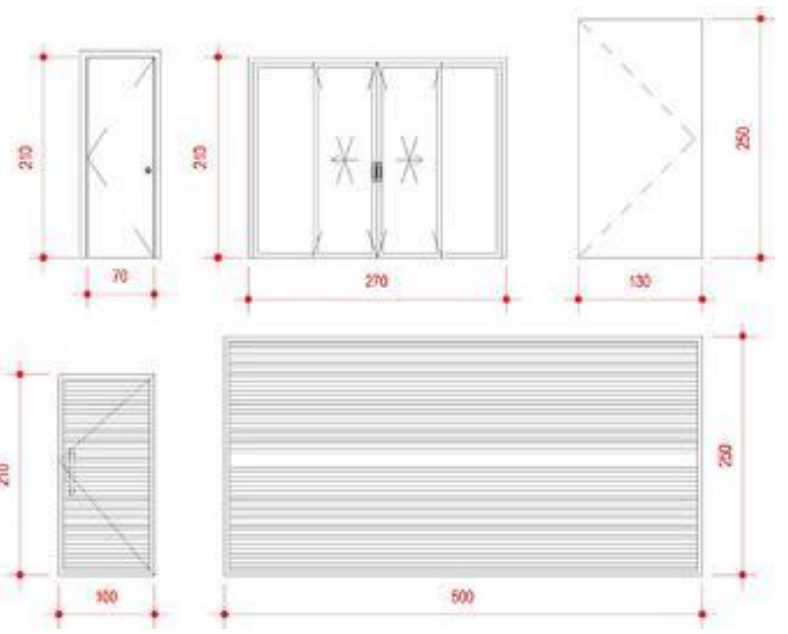

Figura 3: Famílias de portas

Com os elementos de esquadrias determinados, foram definidos os perfis de parede a serem utilizados. O projeto em questão apresenta três espessuras de paredes, sendo elas: $10 \mathrm{~cm}, 15 \mathrm{~cm}$ e $20 \mathrm{~cm}$. Considerou-se desta forma, que as paredes com $10 \mathrm{~cm}$ representam um Drywall finalizado, enquanto as outras duas representam paredes compostas por blocos cerâmicos de $14 \mathrm{~cm}$ e $19 \mathrm{~cm}$, respectivamente. Tal adoção é verdadeira uma vez que se verificou que a parede com espessura de $20 \mathrm{~cm}$ foi atribuída nos limites das geminações dos apartamentos.

As paredes argamassadas foram definidas como mostrado na Tabela 1. As espessuras finais para as paredes constituídas de blocos cerâmicos de $14 \mathrm{~cm}$ e $19 \mathrm{~cm}$ foram: $19 \mathrm{~cm}$ e $24 \mathrm{~cm}$, respectivamente. 
Tabela 1: Composição das paredes argamassadas

\begin{tabular}{c|c|c}
\hline & CAMADA & ESPESSURA (cm) \\
\hline \multirow{4}{*}{ Face Externa } & Pintura, Látex Acrílico & 0,01 \\
\cline { 2 - 3 } & Emassamento, Massa PVC & 0,0 \\
\cline { 2 - 3 } & Reboco & 0,5 \\
\cline { 2 - 3 } & Emboço & 2,0 \\
\hline \multirow{4}{*}{ Núcleo } & Chapisco & 0,0 \\
\cline { 2 - 3 } & Bloco Cerâmico & Variável $(14 \mathrm{~cm}$ ou $19 \mathrm{~cm})$ \\
\cline { 2 - 3 } & Chapisco & 0,0 \\
\cline { 2 - 3 } & Emboço & 2,0 \\
\cline { 2 - 3 } & Reboco & 0,5 \\
\cline { 2 - 3 } & Emassamento, Massa PVC & 0,0 \\
\hline \multirow{2}{*}{ Face Interna } & Pintura, Látex Acrílico & 0,0 \\
\hline
\end{tabular}

A composição do Drywall está apresentada na Tabela 2. Vale notar que por mais que exista uma composição de camadas, a parede de Drywall apresenta a mesma espessura do seu núcleo, $10 \mathrm{~cm}$.

Tabela 2: Composição das paredes em Drywall

\begin{tabular}{c|c|c}
\hline & CAMADA & ESPESSURA (cm) \\
\hline Face Externa & Pintura, Látex Acrílico & 0,0 \\
\hline Núcleo & $\begin{array}{c}\text { Drywall, com manta acústi- } \\
\text { ca }\end{array}$ & 10,0 \\
\hline Face Interna & Pintura, Látex Acrílico & 0,0 \\
\hline
\end{tabular}

Após a definição das paredes argamassadas, foram compostas as paredes com revestimento cerâmico. Estas possuem uma disposição que seguem o projeto de paginação. A Figura 4 apresenta a disposição das peças previstas nas paredes dos dois ambientes.

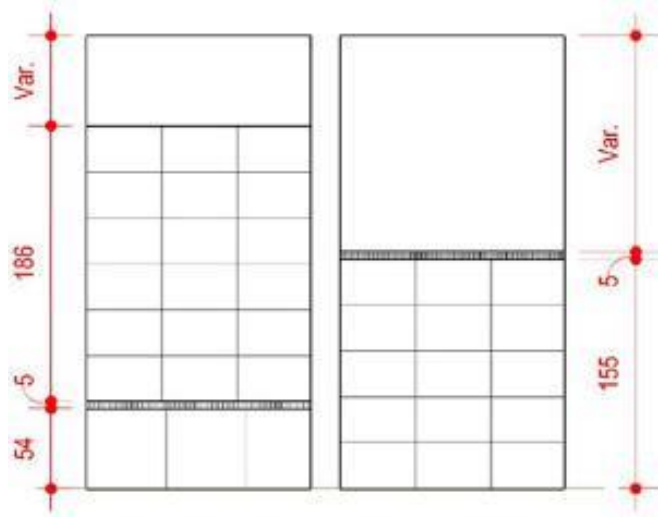

Figura 4: Paginação do revestimento cerâmico dos banheiros e cozinhas, respectivamente

As composições das paredes com revestimento cerâmico foram definidas como exposto pelas Tabelas 3 e 4 . As espessuras finais para as paredes constituídas de blocos cerâmicos de $14 \mathrm{~cm}$ e $19 \mathrm{~cm}$ foram: $19 \mathrm{~cm}$ e $24 \mathrm{~cm}$, respectivamente. A parede em Drywall com revestimento cerâmico apresentou espessura final de $11,5 \mathrm{~cm}$ 
Tabela 3: Paredes argamassadas com revestimento cerâmico em uma face

\begin{tabular}{c|c|c}
\hline & CAMADA & ESPESSURA (cm) \\
\hline \multirow{4}{*}{ Face Externa } & Pintura, Látex Acrílico & 0,0 \\
\cline { 2 - 3 } & Emassamento, Massa PVC & 0,0 \\
\cline { 2 - 3 } & Reboco & 0,5 \\
\cline { 2 - 3 } & Emboço & 2,0 \\
\hline \multirow{4}{*}{ Núcleo } & Chapisco & 0,0 \\
\cline { 2 - 3 } & Bloco Cerâmico & Variável $(14 \mathrm{~cm}$ ou $19 \mathrm{~cm})$ \\
\cline { 2 - 3 } & Chapisco & 0,0 \\
\cline { 2 - 3 } & Emboço & 1,0 \\
\hline \multirow{2}{*}{ Face Interna } & Argamassa Colante & 0,5 \\
\hline
\end{tabular}

Tabela 4: Paredes em Drywall com revestimento cerâmico em uma face

\begin{tabular}{c|c|c}
\hline & CAMADA & ESPESSURA (cm) \\
\hline \multirow{4}{*}{ Face Externa } & Pintura, Látex Acrílico & 0,0 \\
\cline { 2 - 3 } & Emassamento, Massa PVC & 0,0 \\
\cline { 2 - 3 } & Reboco & 0,5 \\
\cline { 2 - 3 } & Emboço & 2,0 \\
\hline \multirow{4}{*}{ Núcleo } & Chapisco & 0,0 \\
\cline { 2 - 3 } & Bloco Cerâmico & Variável $(14 \mathrm{~cm} \mathrm{ou} 19 \mathrm{~cm})$ \\
\cline { 2 - 3 } & Chapisco & 0,0 \\
\cline { 2 - 3 } & Emboço & 1,0 \\
\hline \multirow{2}{*}{ Face Interna } & Peça Cerâmica & 0,5 \\
\hline
\end{tabular}

As famílias de parede com os revestimentos definidos, tanto argamassados quanto cerâmicos, podem ser vistos na Figura 5. Na ordem da esquerda para a direita: paredes com revestimento argamassado (1 a 3 ), paredes cerâmicas aplicadas nos banheiros (4 a 6) e, paredes cerâmicas aplicadas nas cozinhas ( 7 a 9). Foram criados perfis com os três materiais de núcleo disponíveis: Drywall (hachura cruzada), Bloco cerâmico de 14 cm (hachura dupla paralela), e Bloco cerâmico de $19 \mathrm{~cm}$ (hachura dupla paralela). 


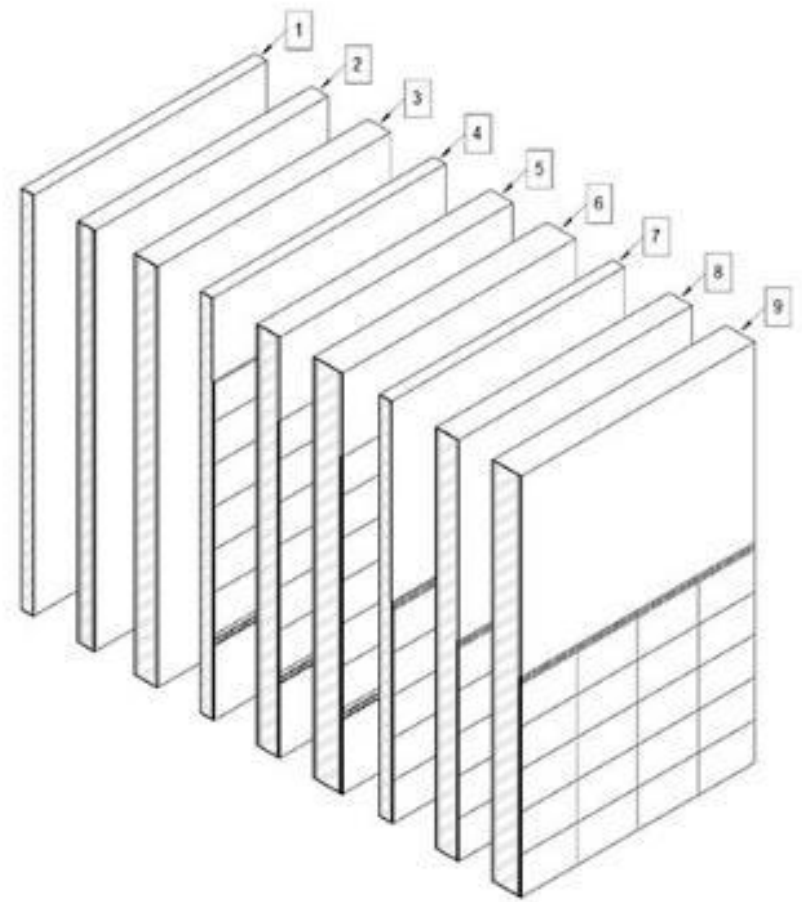

Figura 5: Paredes revestidas

Seguiu-se então com a determinação das famílias de piso. A Figura 6 apresenta os três tipos de peças aplicadas no projeto. Nos banheiros a peça aplicada corresponde a um Porcelanato 54 x $54 \mathrm{~cm}$ (à esquerda), nos demais ambientes foi previsto um Porcelanato $60 \times 60 \mathrm{~cm}$ (no centro), e as soleiras de todas as portas uma peça em Granito (à direita). Foi considerado uma camada de assentamento de argamassa colante de $1 \mathrm{~cm}$ onde as peças onde foram colocadas as peças, com espessura de $1 \mathrm{~cm}$.

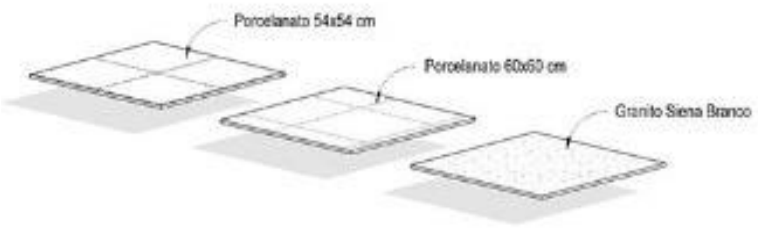

Figura 6: Pisos

Após a determinação das principais famílias foram definidos os níveis do projeto. Os níveis servem como referência para a locação dos objetos no eixo referente à altura, tendo como base um ponto conhecido (no caso o Terreno). A Figura 7 mostra os níveis, definidos em osso (N.O.2 - Representa o nível dos elementos estruturais sem revestimento), com base nas informações extraídas do arquivo em DWG. 


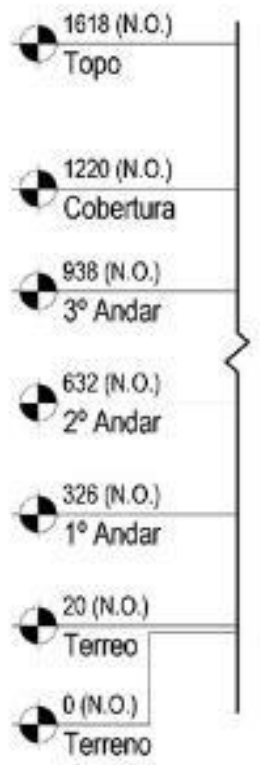

Figura 7: Níveis

Com os níveis definidos, foi iniciado o lançamento. O desenho referente ao Pavimento Tipo foi importado para o nível $1^{\circ}$ Andar. Os elementos de parede foram então lançados, nas suas correspondentes posições conforme espessura. A altura das paredes é definida pelos Níveis estabelecidos anteriormente. Na sequência foram posicionadas as Janelas e Portas. O resultado parcial do $1^{\circ}$. Andar pode ser visto na Figura 8. A fachada do edifício prevê uma cortina de vidro, a mesma foi modelada de modo a atender as dimensões do projeto.

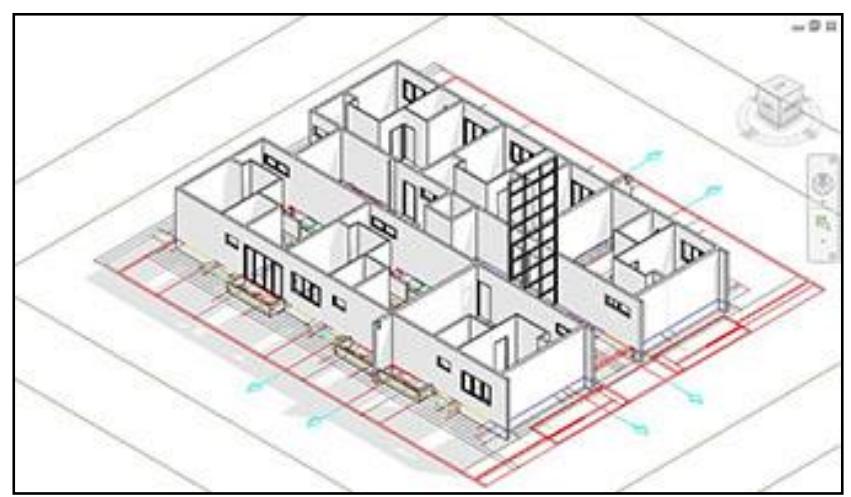

Figura 8: $1^{\circ}$ Andar com esquadrias

Após a inserção das esquadrias, foram inseridos os pisos, as bancadas e forros das cozinhas e banheiros. Bem como os guarda-corpos e a escada. Os elementos de piso foram adicionados respeitando as elevações e rebaixos previstos no projeto de paginação. A Figura 9 apresenta a paginação do piso e os elementos adicionados. 


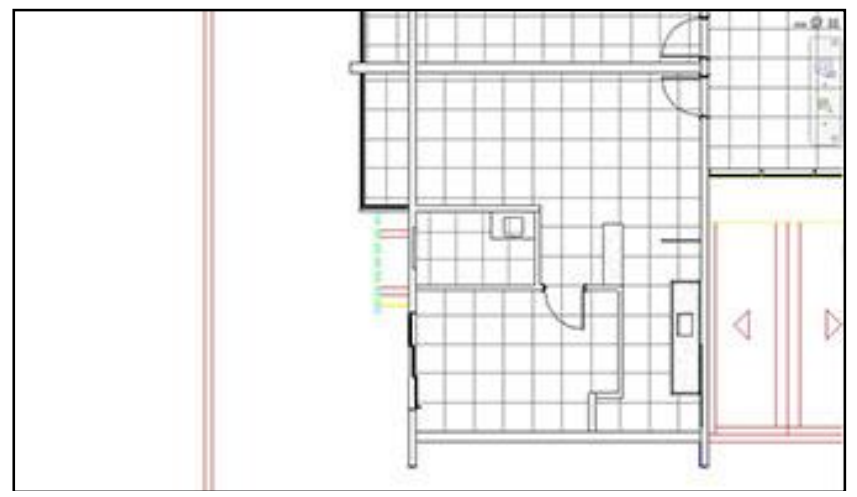

Figura 9: $1^{\circ}$ Andar (detalhe de um apartamento)

Com a finalização da adição dos elementos do $1^{\circ}$ Andar, foram atualizados os perfis de parede para aqueles com maior nível de detalhamento definidos anteriormente. Essa modificação tardia permitiu um menor consumo de recursos computacionais durante o lançamento do pavimento tipo.

A geometria do andar tipo foi então copiada para os níveis superiores que comportam apartamentos ( $2^{\circ}$ Andar e $3^{\circ}$ Andar). O processo de importação de desenho e lançamento de elementos foi repetido nos níveis Térreo e Cobertura. No topo das lajes impermeabilizadas foi colocada uma membrana que representa a inclinação $i=2 \%$. As telhas e calhas da cobertura foram lançadas conforme previsto em projeto. Não foram lançados os elementos estruturais neste arquivo, uma vez que estes pertencem à disciplina estrutural. Na Figura 10 é possível ver a vista em perspectiva da arquitetura do prédio.

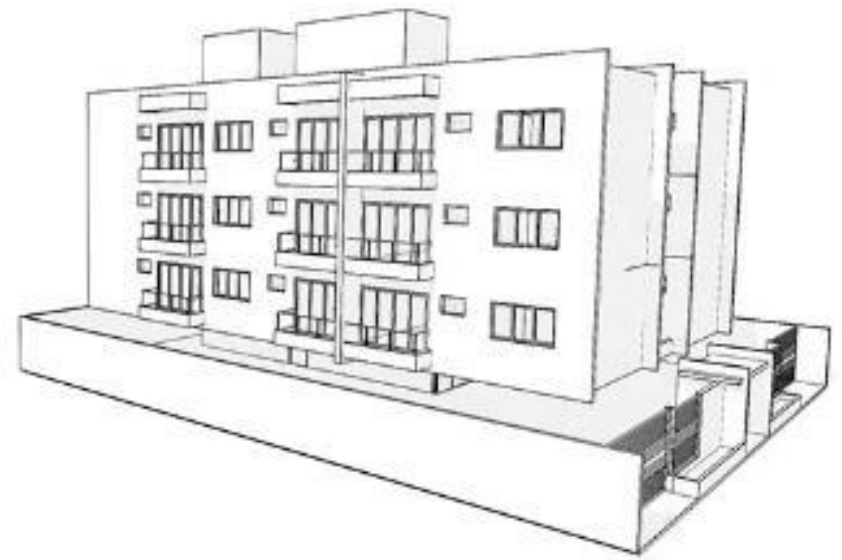

Figura 10: Arquitetura (vista em perspectiva)

\subsection{Hidrossanitário}

Os projetos referentes ao hidrossanitário fornecidos pelo escritório contemplam os sistemas de Água Fria e Esgoto Sanitário, os quais foram utilizados na modelagem. Como as referências utilizadas carecem de detalhes para a locação das peças, as mesmas foram alocadas de modo a visualmente representarem aquilo disposto nos projetos.

Para o modelo hidrossanitário foi utilizado o template fornecido pela Tigre ${ }^{\circledR}$ S.A. e distribuído pela OFCDesk LLC. O arquivo já possui todas as famílias necessárias para o lançamento do projeto, referenciadas ao catálogo de peças existentes da Tigre, o que facilitou o lançamento da disciplina.

Inicialmente, foram definidos os níveis do projeto analogamente ao modelo arquitetônico (como visto na Figura 9). O modelo arquitetônico foi então inserido no arquivo através de um link. Tal recurso permite importar os elementos modelados em outro arquivo para que estes sejam utilizados como referência de posicionamento. Uma vez que os arquivos foram divididos em disciplina, tal mecanismo foi necessário.

Foram então lançados os aparelhos e tubos referentes ao projeto de água fria em um apartamento. Como o "template" já possui definidas as peças de conexão, as mesmas são dispostas automaticamente com o traçado dos tubos. 
O lançamento dos aparelhos e tubos de esgoto sanitário foi feito na sequência. As inclinações dos tubos, como definido em norma, foram respeitadas. O projeto hidrossanitário apresentou os dois sistemas separadamente, assim, para este lançamento os elementos de água fria foram ocultados.

Com a finalização do lançamento dos sistemas de um apartamento, foi feita a cópia dos elementos para as demais unidades no mesmo pavimento. A Figura 11 mostra a disposição final dos elementos no $1^{\circ}$ Andar.

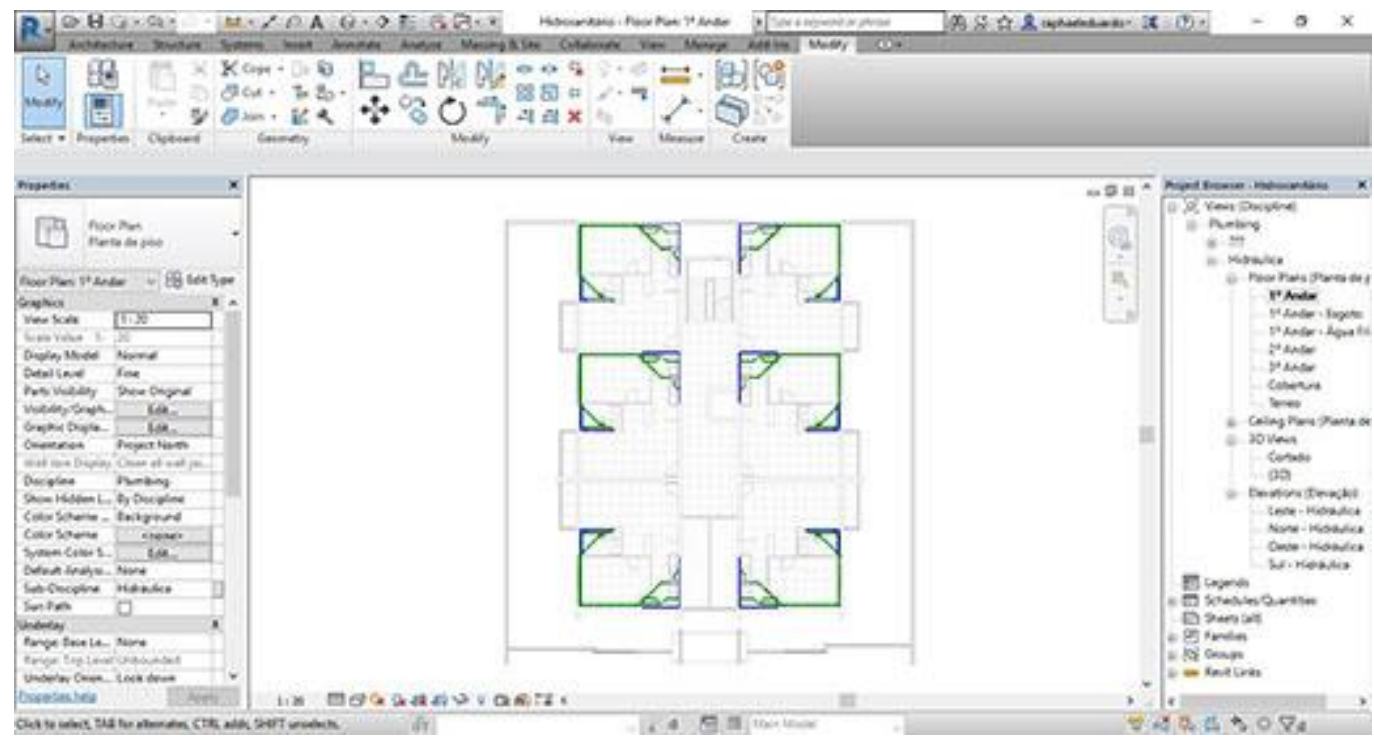

Figura 11: Revit® 2017 (lançamento hidrossanitário no $1^{\circ}$. Andar)

Os elementos modelados no $1^{\circ}$ Andar foram então copiados para os níveis superiores $\left(2^{\circ}\right.$ Andar e $3^{\circ}$ Andar). Na sequência, o processo de modelagem foi repetido para os elementos presentes no pavimento Térreo e Cobertura. Foram incluídas as caixas de passagem de esgoto com direção à rede de coleta, bem como a tubulação de chegada de água potável passando pelos sistemas de adução e armazenamento. O barrilete foi modelado conforme definido no projeto. A Figura 12 mostra a disposição final dos elementos modelados.

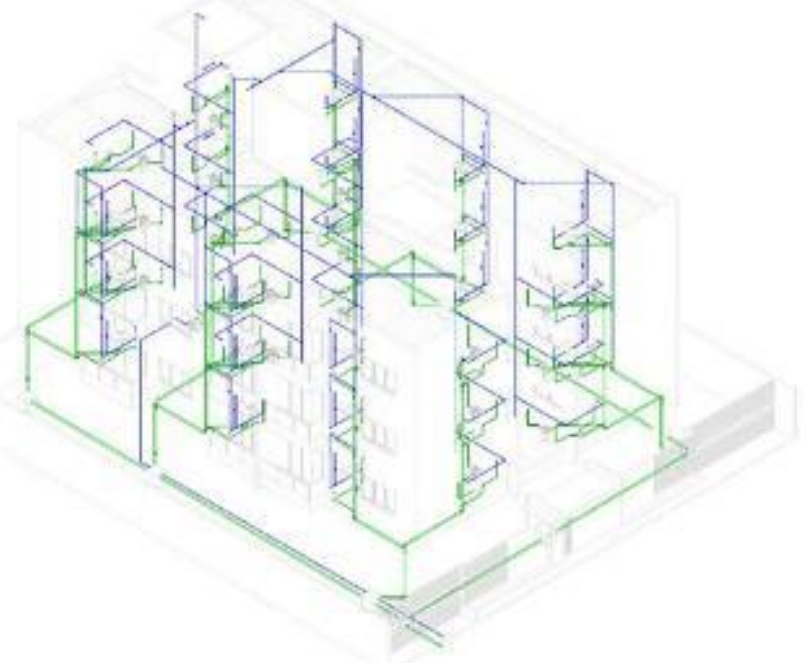

Figura 12: Modelo hidrossanitário finalizado

\subsection{Estrutural}

O modelo estrutural foi construído tendo como base o "template" também utilizado no desenvolvimento da arquitetura. Neste, foram importadas as famílias: Pilar de Concreto Retangular, Viga de Concreto Retangular. Além destes, foram inseridas ainda as famílias de Bloco sobre Estaca que contemplem as necessidades do projeto. Já estavam presentes as famílias básicas para desenvolvimento das lajes. 
Os níveis foram definidos conforme apresentado os arquivos fornecidos (como visto na Figura 7). O projeto estrutural utiliza como referência linhas de eixo, foi então escolhida uma interseção entre duas linhas no projeto arquitetônico para servir como ponto de origem do lançamento. Com o ponto A1 traçado, foi feita a definição dos demais. Na Figura 13 é possível visualizar os eixos lançados.

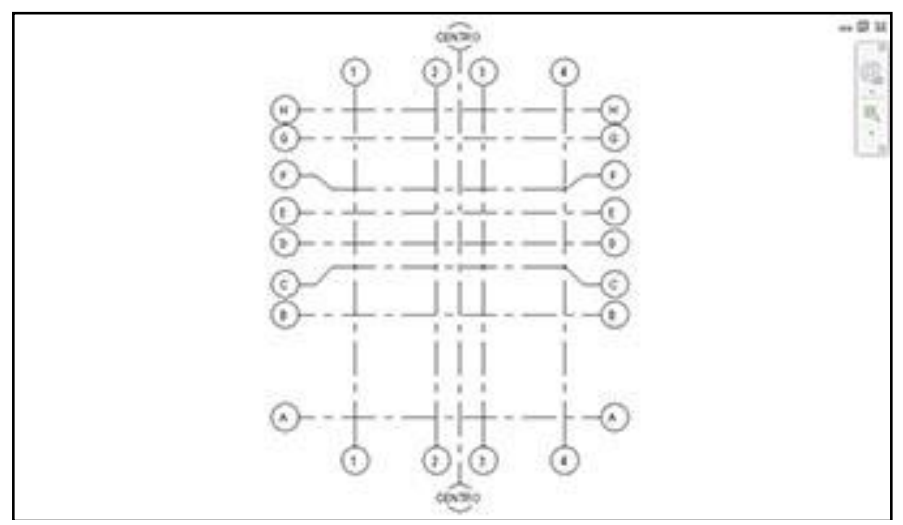

Figura 13: Definição dos eixos de referência

Seguindo, então, as informações do projeto estrutural (cedido pela construtora), foram lançados os elementos presentes no nível Térreo. A geometria dos elementos definidos pode ser vista na Figura 14.

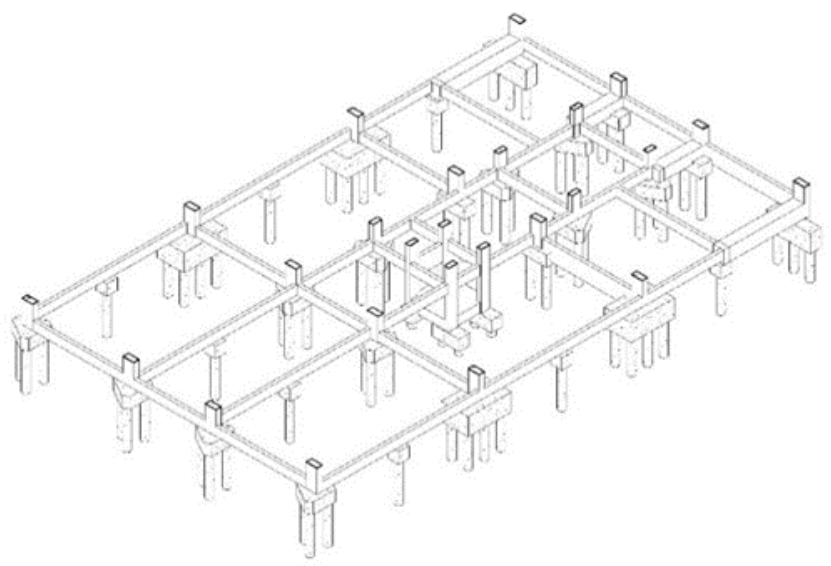

Figura 14: Elementos estruturais do nível Térreo

O processo de lançamento de pilares e vigas foi repetido nos demais níveis de modo a contemplar todos os elementos. Onde tal função se mostrava possível, foram feitas cópias entre os níveis.

O projeto estrutural apresenta lajes maciças e nervuradas em duas direções. As lajes maciças foram lançadas de maneira simples, respeitando os contornos e rebaixos (onde existem). As lajes nervuradas foram modeladas sendo divididas em 3 partes: capa, nervura e enchimento. Tal divisão permite que sejam feitas análises mais refinadas de interferência, uma vez que a modelagem representa com fidelidade a composição do conjunto.

Na Figura 15 pode ser visto um detalhe dos dois tipos de lajes modeladas em meio aos elementos estruturais antes traçados (vigas e pilares). Os elementos quadriculados representam o material de enchimento utilizado, no caso Poliestireno Expandido (EPS). Por mais que os componentes se complementem, os mesmos foram modelados de modo a não se sobreporem. Os elementos em concreto isolados podem ser vistos a direita do detalhe em azul na imagem supracitada. 


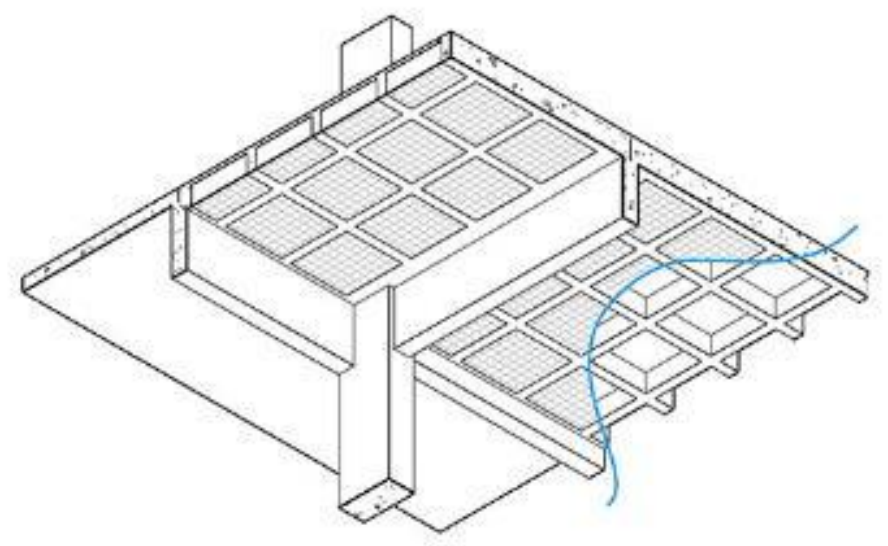

Figura 15: Lajes

Com o lançamento das lajes, foi finalizada a modelagem de toda a geometria presente no projeto estrutural. A Figura 16 mostra os elementos lançados na interface do programa.

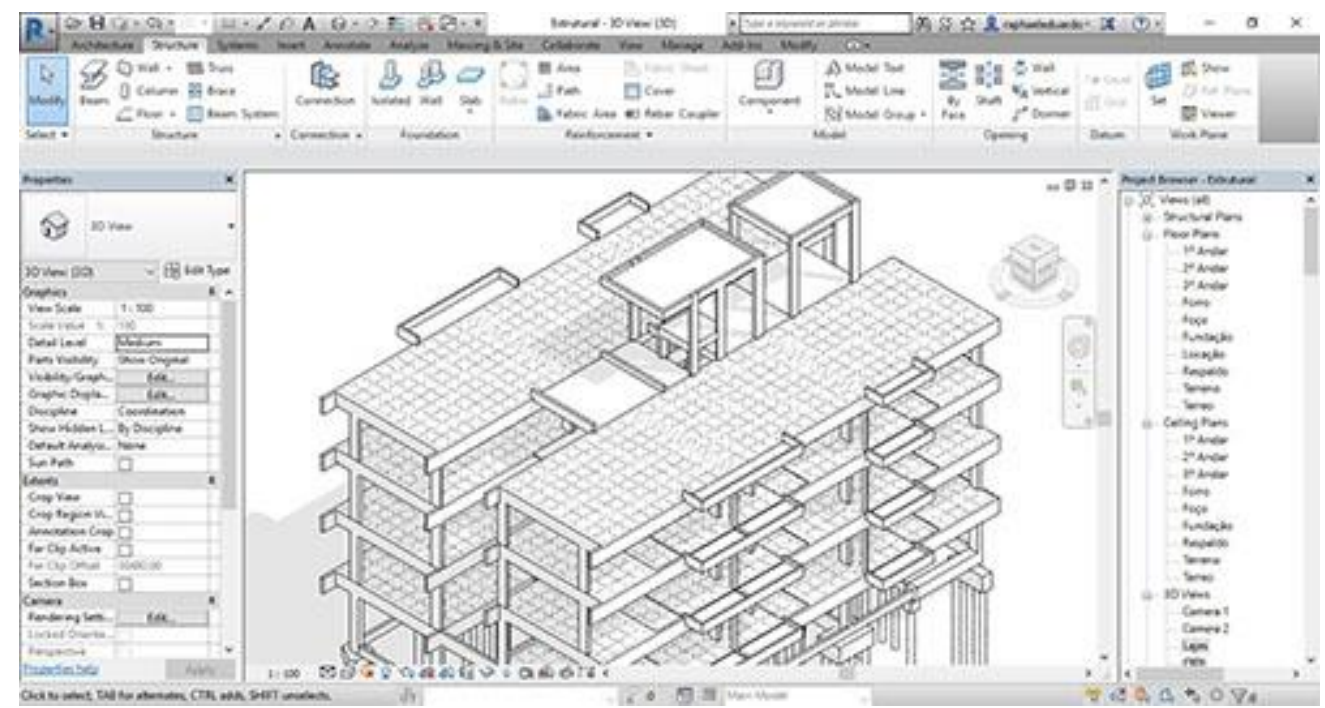

Figura 16: Revitß 2017 (modelo estrutural finalizado)

\subsection{Realização das análises através do software de compatibilização}

Após a criação dos modelos tridimensionais a partir dos projetos do edifício, fez-se a integração dos mesmos em uma plataforma única (Figura 17), com a finalidade de realizar a análise de interferências, também realizada por LI et al [7]. Para tal, foi utilizado o software de gerenciamento de projetos Navisworks Manage ${ }^{\circledR}$ 2017. A integração dos projetos neste software se dá através da importação dos arquivos dentro do programa, dentre os diversos formatos de arquivos suportados estão: 3D Studio (.3ds), CIS/2, DWF, DWG, IFC, Revit (.rvt), Sketchup (.skp), entre outros. Como entre os formatos de arquivo suportados está o formato do Revit, em que foram desenvolvidos os modelos, foi escolhido utilizar este formato, não necessitando realizar antes a conversão do Revit para o IFC. 


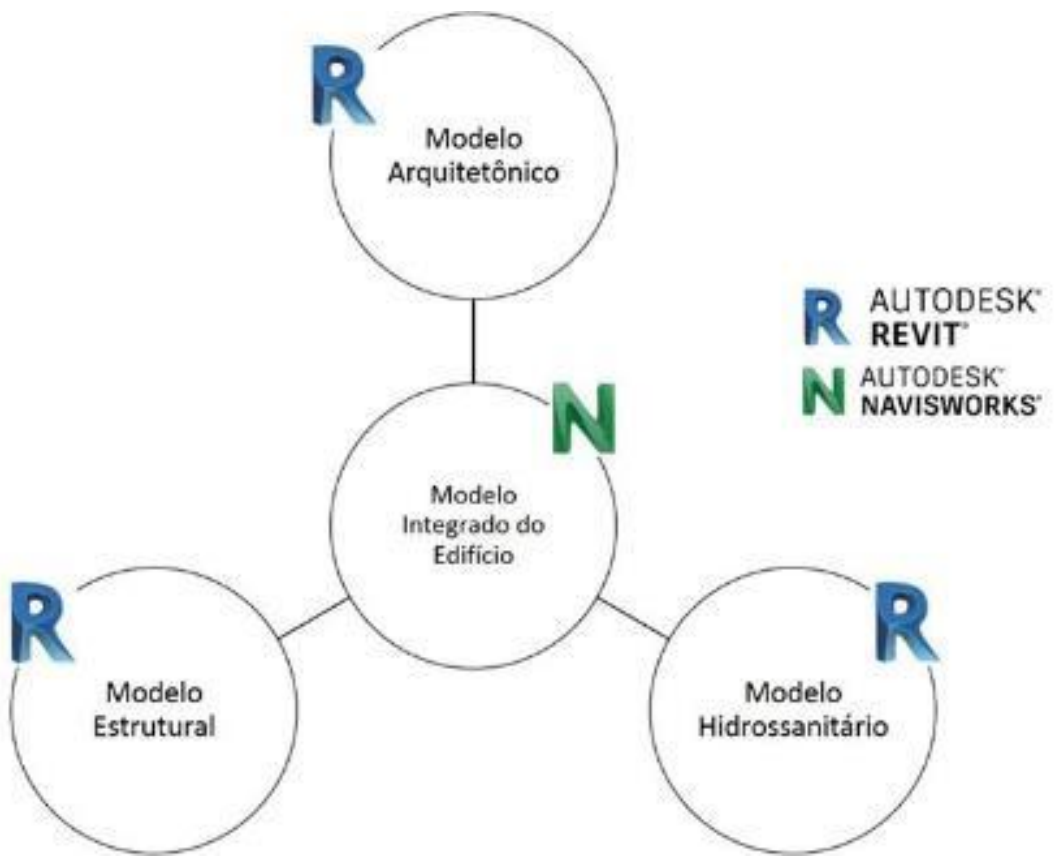

Figura 17: Integração dos projetos

Com o modelo integrado pronto (Figura 18), foi realizada a análise de interferências utilizando a ferramenta Clash Detective do software. Através desse recurso, foram realizadas as análises apresentadas na Tabela 5, escolhendo na ferramenta do programa os elementos de quais níveis seriam analisados, como a análise de interferência entre o forro, pertencente ao modelo arquitetônico, e as peças e tubulações do projeto hidrossanitário. Ao determinar os parâmetros da análise, foi escolhido o tipo Hard, que determina interferência direta entre os componentes escolhidos, com tolerância máxima de $1 \mathrm{~mm}$.

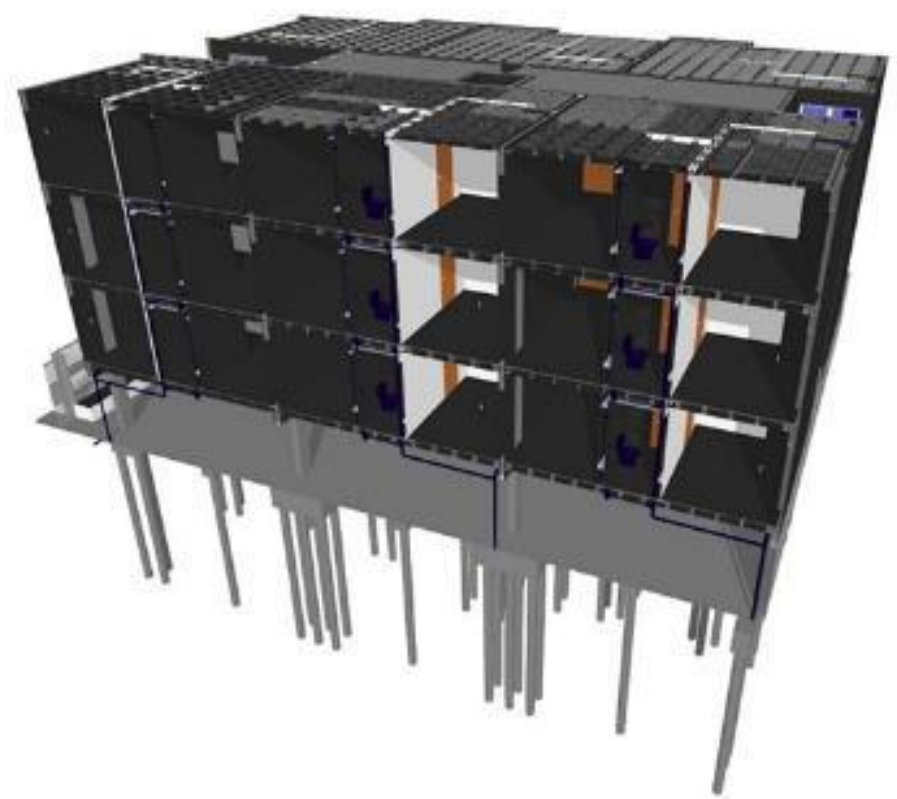

Figura 18: Modelo integrado do edifício

\subsection{Análises realizadas}

Com a utilização da ferramenta Clash Detective do software Navisworks Manage ${ }^{\circledR}$ é possível selecionar todos os elementos que se deseja analisar as interferências. Foram realizadas as combinações de todos elementos referentes a fundação, pilares, vigas, lajes e forros com os elementos do projeto hidrossanitário (Tabela 5). 
Tabela 5: Interferências entre os elementos

\begin{tabular}{c|c}
\hline SELEÇÃO 1 & SELEÇÃO 2 \\
\hline Proj. Fundação & Proj. Hidrossanitário \\
\hline Proj. Estrutural (Pilares) & Proj. Hidrossanitário \\
\hline Proj. Estrutural (Vigas) & Proj. Hidrossanitário \\
\hline Proj. Estrutural (Lajes) & Proj. Hidrossanitário \\
\hline Proj. Arquitetura (Forros) & Proj. Hidrossanitário \\
\hline Proj. Hidrossanitário (Água Fria) & Proj. Hidrossanitário (Esgoto Sanitário) \\
\hline
\end{tabular}

No caso de fundações rasas é comum o conflito com tubulações, caixas de esgoto e passagem. No modelo dimensionado preocupou-se com os blocos de coroamento das estacas, por isso fez-se a análise.

No modelo fez-se a análise das lajes nervuradas em duas direções (desconsiderando a "capa" e o enchimento) e das lajes maciças. A preocupação neste caso foi com a interposição das caixas de esgoto com as nervuras da laje, a fim de verificar se existiu ou não a preocupação de compatibilização por parte do projetista.

Foi realizada a análise do forro com o sistema hidrossanitário, pois é recorrente o rebaixamento do forro diante do que foi definido em projeto.

Nos resultados das análises foram feitas tabelas separando os quantitativos. Primeiramente, no sistema hidrossanitário foi dividido em sistema de água fria e esgoto sanitário. Depois, para mais detalhes, foram separadas as conexão e tubulação e, em alguns casos, entraram outras peças especiais como, por exemplo, a caixa de gordura.

Após a realização das análises os resultados obtidos foram exportados em formato de relatório para a análise dos resultados.

Criou-se um cenário cujos elementos identificados como interferências foram classificados em dois tipos: percebidos em projeto ou revelados apenas na execução. O critério escolhido para essa classificação é o da proximidade entre os elementos coincidentes. Algumas situações, por exemplo, a tubulação pode passar no meio da viga, porém em outras, apenas parte da tubulação estava passando sobre a viga, sendo mais difícil de ser visto em projeto. Portanto, no primeiro caso a interferência é de projeto e no segundo caso a interferência seria vista apenas na execução.

\section{RESULTADOS E DISCUSSÃO}

\subsection{Modelagem 3D}

O resultado direto do desenvolvimento do banco de dados de informações inseridas na plataforma BIM é um modelo tridimensional. O modelo representa com fidelidade todos os dados das disciplinas contempladas. Especificamente neste trabalho: arquitetura, hidrossanitário e estrutural.

A tridimensionalidade permite uma maior maleabilidade dos dados, uma vez que as noções passadas às equipes de construção transcendem àquelas existentes nas referências impressas. Podendo, de tal forma, existir o acompanhamento da construção e a solução de dúvidas na fase de construção diretamente no modelo 3D. Além da extração de dados concisos referentes à quantificação de materiais e elementos, inúmeras análises podem ser feitas. Cabe citar, principalmente, as análises de interferências (foco do artigo), análises de ventilação e análises de iluminação .

Os modelos Estrutural, Arquitetônico e Hidrossanitário finais são mostrados, respectivamente, na Figura 19. É possível observar que todos os elementos estão alinhados no espaço. 


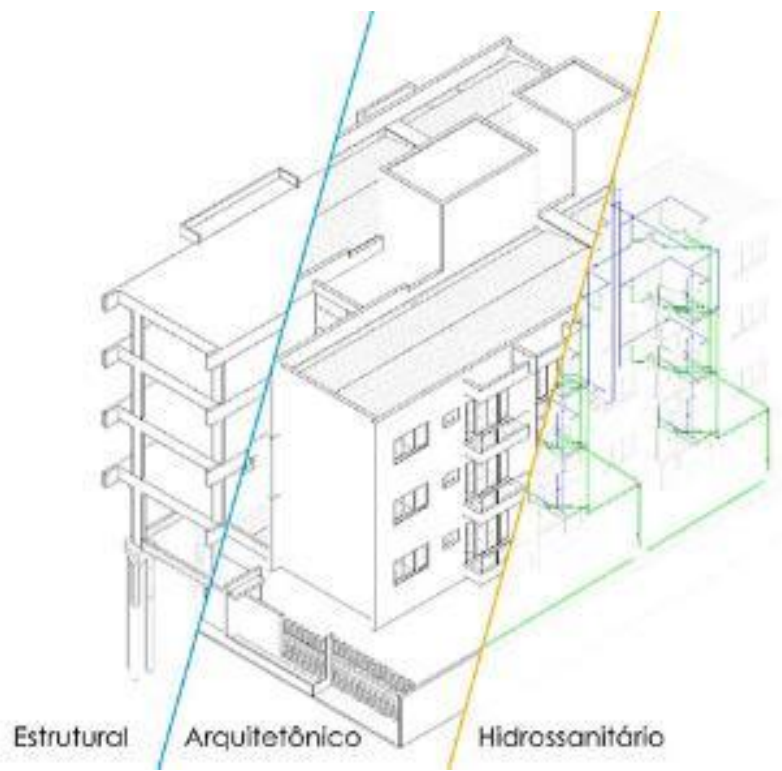

Figura 19: Modelagem do edifício

A Figura 20 apresenta um paralelo entre o modelo construído com base nos projetos fornecidos e o prédio finalizado. Cabem destacar as mudanças de projeto no ato da execução, como é possível ver na alteração da localização do reservatório e modificações nas sacadas. Como não existe um as built, estas alterações não foram transferidas para o banco de dados produzido pela modelagem em BIM.

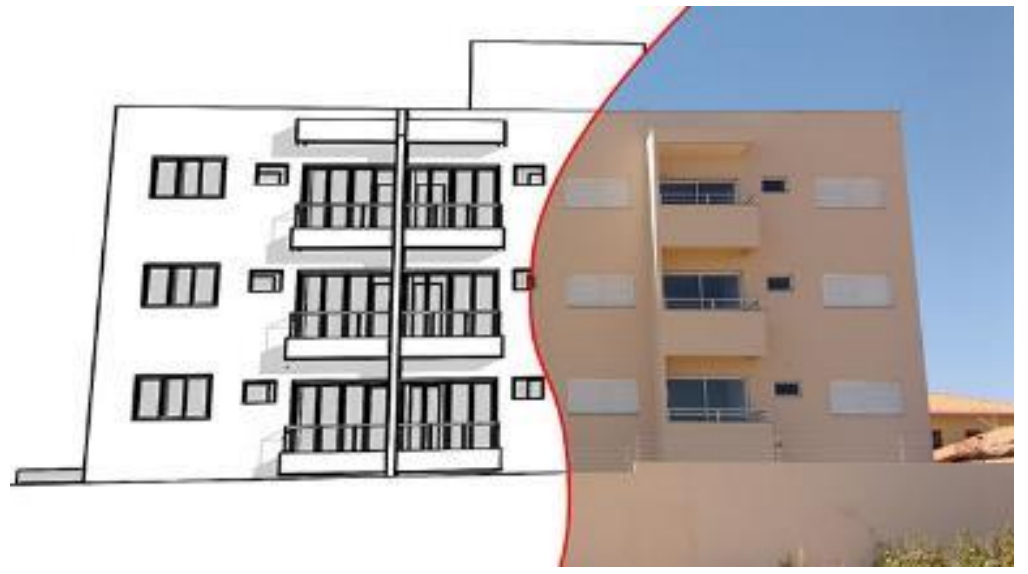

Figura 20: Modelo tridimensional x Edifício finalizado

Os projetos arquitetônico e estrutural foram modelados conforme as informações neles presentes. Ambos apresentaram informações conflitantes entre seus próprios desenhos. A existência de tais conflitos dificultou o processo modelagem, uma vez que nem todos os desenhos apresentavam informações concisas e coerentes. Dentre tais, é possível comentar a falta da representação dos reservatórios em alguns cortes arquitetônicos, a falta de referência de alguns níveis estruturais, e o não detalhamento do paisagismo no pavimento térreo nas plantas corretas.

A falta de informações no projeto hidrossanitário dificultou a execução do modelo. Não existe referência ao sistema de ventilação de esgoto. Em vários locais foi necessária uma análise criteriosa para que houvesse o entendimento da disposição das peças. Aliado a isso, não foram apresentados detalhes para a execução, além da falta de indicação correta das inclinações e diâmetro dos tubos, como mostrado nas Figuras 21 e 22. Os elementos lineares foram modelados atendendo as inclinações mínimas exigidas por norma. 


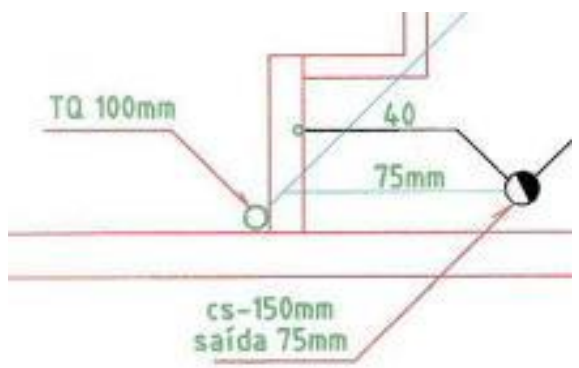

Figura 21: Detalhe Hidrossanitário da Cozinha (modelo convencional em 2D)

Fonte: ROCHA [12]

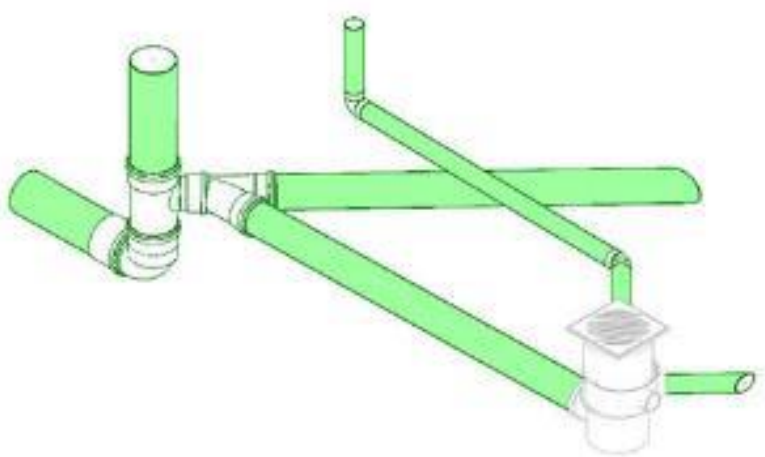

Figura 22: Isométrico Hidrossanitário da Cozinha modelado em BIM

\subsection{Análise de interferências}

Confrontando os itens dos projetos foram obtidos um total de 798 interferências (Tabela 6).

Tabela 6: Combinações e números de interferências

\begin{tabular}{|c|c|}
\hline COMBINAÇÕES DE PROJETOS & № DE INTERFERÊNCIAS \\
\hline Fundação x Hidrossanitário & 2 \\
\hline Pilar x Hidrossanitário & 82 \\
\hline Viga $\mathrm{x}$ Hidrossanitário & 109 \\
\hline Laje x Hidrossanitário & 391 \\
\hline Forro x Hidrossanitário & 148 \\
\hline Tubulações de Água fria x Esgoto Sanitário & 66 \\
\hline Total & 798 interferências \\
\hline
\end{tabular}

\subsubsection{Interferências entre projetos de fundação e hidrossanitário}

Foram obtidas 02 (duas) interferências analisando esses dois projetos. Esse número baixo pode ter ocorrido pela planta do pavimento Térreo da construção servir apenas de estacionamento, ou seja, não possui um sistema de esgoto sanitário carregado como nos pavimentos tipo, além da fundação ser profunda.

Os conflitos se deram pelo encontro da tubulação de esgoto PVC $40 \mathrm{~mm}$ com o bloco de coroamento das estacas (Figura 23). Neste caso a interferência poderia até ser desconsiderada se deslocasse o tubo, não havendo qualquer problema ao sistema. 


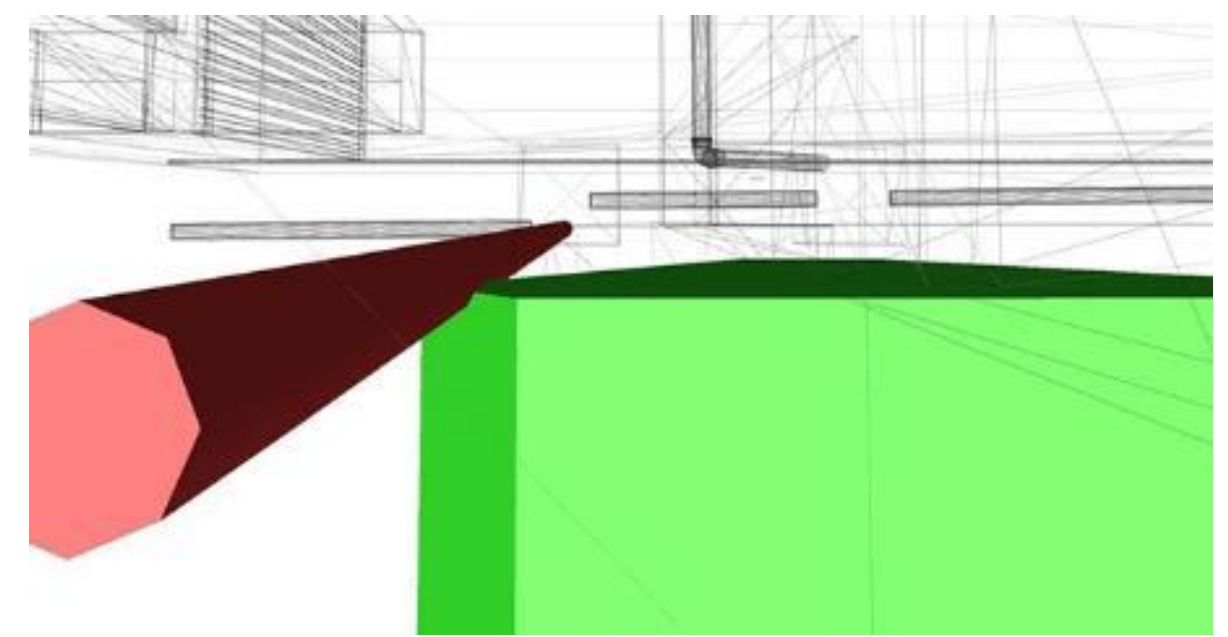

Figura 23: Tubulação de esgoto com bloco de fundação

\subsubsection{Interferências entre projeto estrutural (pilares) e hidrossanitário}

Foram obtidas 82 (oitenta e dois) interferências analisando esses dois projetos, como pode ser visto na Tabela 7.

Tabela 7: Quantidade de interferências entre projetos estrutural (pilares) e hidrossanitário

\begin{tabular}{|c|c|}
\hline TIPO & QUANTIDADE \\
\hline Projeto de Esgoto Sanitário x Projeto Estrutural (Pilares) & 19 \\
\hline Projeto de Água Fria x Projeto Estrutural (Pilares) & 63 \\
\hline Total & 82 \\
\hline
\end{tabular}

Subdividindo os sistemas em seus componentes, como conexões e tubulações, tem-se a Tabela 8.

Tabela 8: Quantidade de interferências entre conexões e tubulações com pilares

\begin{tabular}{l|c}
\hline \multicolumn{1}{c|}{ TIPO } & QUANTIDADE \\
\hline Conexões de Esgoto Sanitário x Pilares & 4 \\
\hline Tubulação de Esgoto Sanitário x Pilares & 15 \\
\hline Conexões de Água Fria x Pilares & 13 \\
\hline Tubulação de Água Fria x Pilares & 50 \\
\hline Total & 82 \\
\hline
\end{tabular}

Analisando os resultados das Tabelas 7 e 8 nota-se que a interferência entre tubulação de água fria e pilares foi a que mais ocorreu (Figura 24). Este tipo de interferência não é previsto em norma e a forma de solucioná-lo seria alterar o trajeto da tubulação, ou seja, adicionar mais conexões para desviar dos pilares, o que, possivelmente, diminuiria a pressão da água na tubulação e aumentaria o gasto de materiais. 


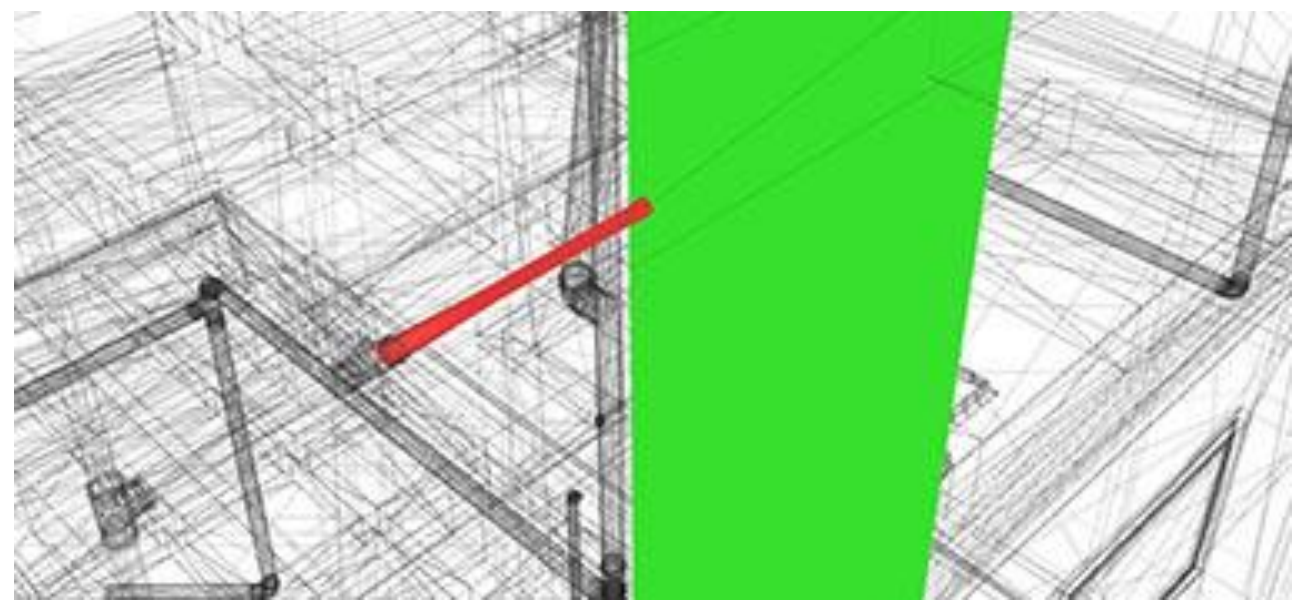

Figura 24: Interferência entre tubulação de água fria e pilar

Outra interferência ocorrida foi entre a tubulação de esgoto sanitário que coincidiu com o pilar (Figura 25).

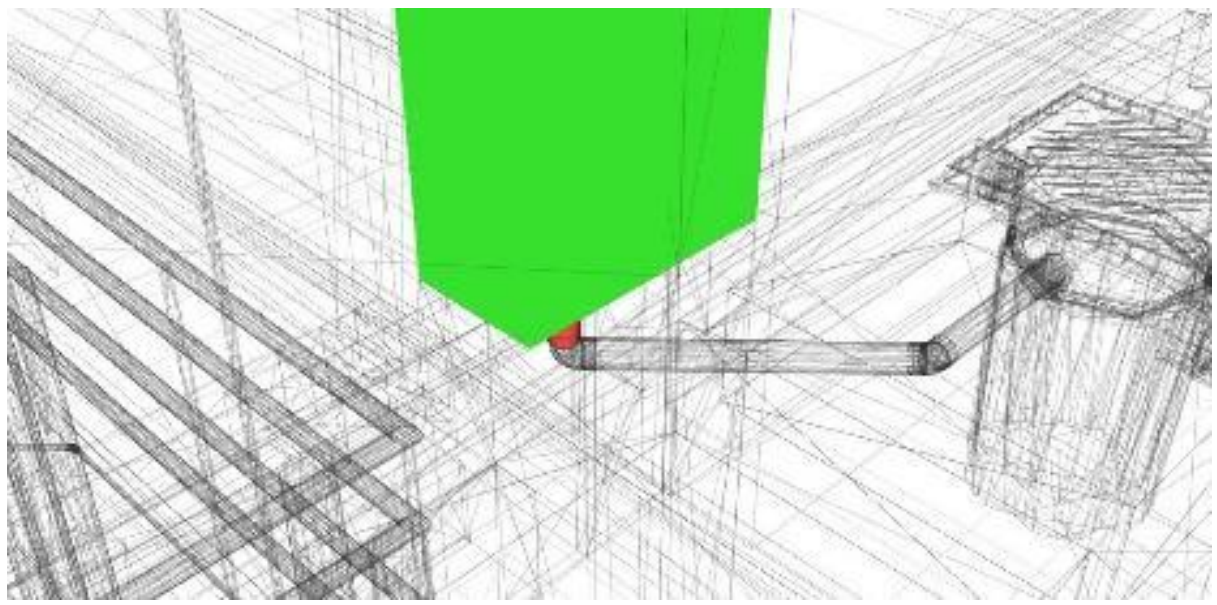

Figura 25: Interferência entre tubulação de esgoto sanitário e pilar

\subsubsection{Interferências entre projeto estrutural (vigas) e hidrossanitário}

Foram obtidas 109 (cento e nove) interferências analisando esses dois projetos, como pode ser visto na Tabela 9.

Tabela 9: Quantidade de interferências entre projeto estrutural (vigas) e hidrossanitário

\begin{tabular}{r|c}
\hline \multicolumn{1}{c|}{ TIPO } & QUANTIDADE \\
\hline Projeto de Esgoto Sanitário x Projeto Estrutural (Viga) & 72 \\
\hline Projeto de Água Fria x Projeto Estrutural (Viga) & 37 \\
\hline Total & 109 \\
\hline
\end{tabular}

A Tabela 10 apresenta a subdivisão dos sistemas em seus componentes, como conexões e tubulações.

Tabela 10: Quantidade de interferências das conexões e tubulações com vigas

\begin{tabular}{l|c}
\hline \multicolumn{1}{c|}{ TIPO } & QUANTIDADE \\
\hline Conexões de Esgoto Sanitário x Vigas & 57 \\
\hline Tubulação de Esgoto Sanitário x Vigas & 15 \\
\hline Conexões de Água Fria x Vigas & 7 \\
\hline Tubulação de Água Fria x Vigas & 30 \\
\hline Total & 109 \\
\hline
\end{tabular}


Analisando os resultados das Tabelas 9 e 10 nota-se que a interferência entre conexões de esgoto sanitário e vigas é a que mais ocorreu (Figura 26). Esses números podem se justificar devido a tubulação ser embutida na parede e as dimensões da viga coincidirem com a largura da parede. Para corrigir essa interferência deveriam ser propostos shafts para as tubulações verticais.

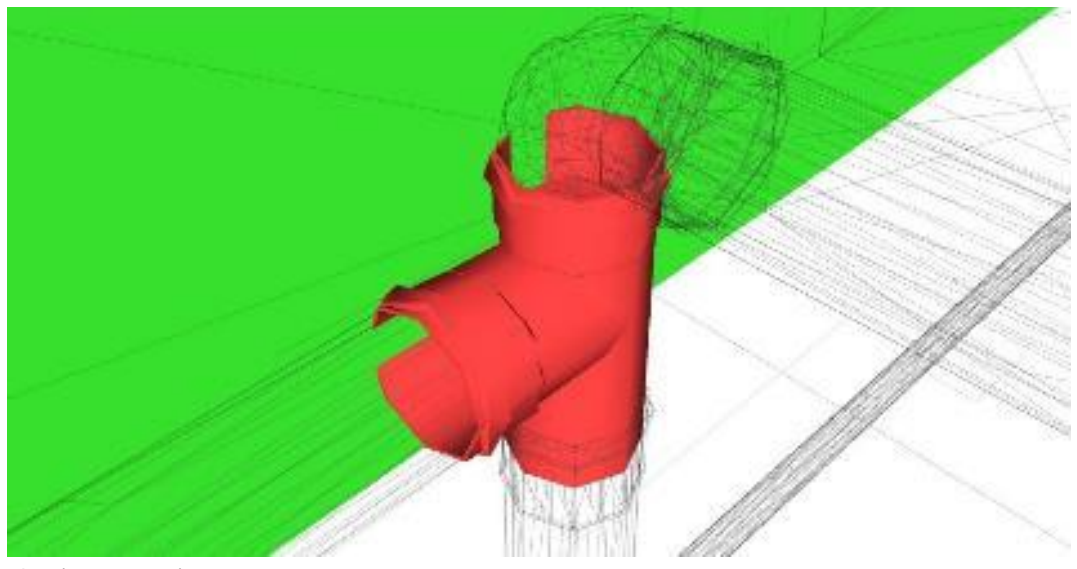

Figura 26: Interferência entre viga e conexão

Outra ocorrência que geralmente acontece nas obras é a passagem de tubulação em vigas (Figura 27). Isso é previsto em norma e pode ser calculado, mas nos projetos não havia nada prevendo essas interferências.

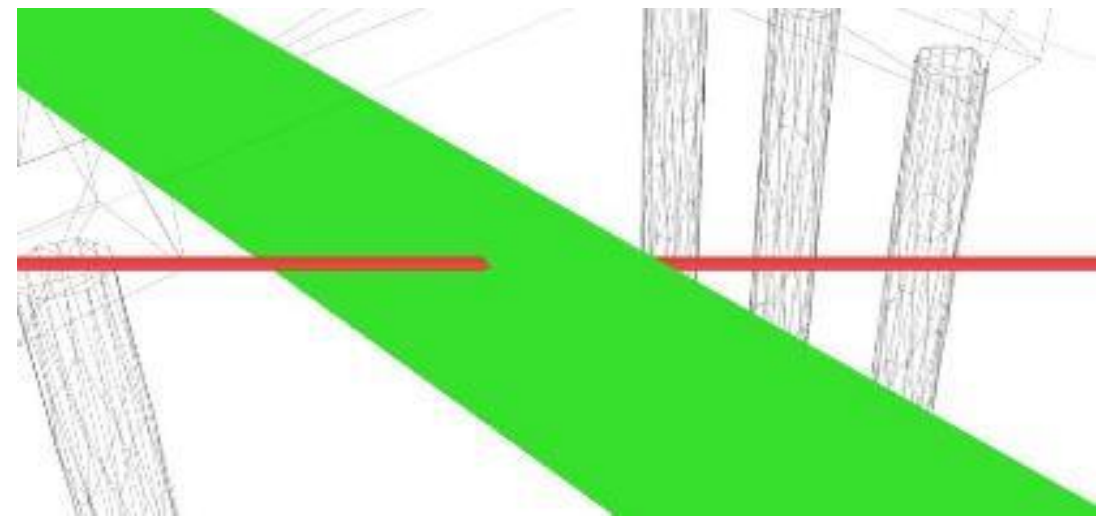

Figura 27: Interferência de tubulação de água fria com viga

\subsubsection{Interferências entre projeto estrutural (lajes) e hidrossanitário}

Foram obtidos 391 (trezentos e noventa e um) interferências analisando esses dois projetos, como pode ser visto na Tabela 11.

Tabela 11: Quantidade de interferências entre projeto estrutural (lajes) e hidrossanitário

\begin{tabular}{|c|c|}
\hline TIPO & QUANTIDADE \\
\hline Projeto de Esgoto Sanitário x Projeto Estrutural (Lajes) & 296 \\
\hline Projeto de Água Fria x Projeto Estrutural (Lajes) & 95 \\
\hline Total & 391 \\
\hline
\end{tabular}

A Tabela 12 apresenta a subdivisão dos sistemas por seus componentes como, por exemplo, as conexões, caixa sifonada e tubulações. 
Tabela 12: Quantidade de interferências das conexões, caixas e tubulações com lajes

\begin{tabular}{|c|c|}
\hline TIPO & QUANTIDADE \\
\hline Conexões de Esgoto Sanitário x Lajes & 64 \\
\hline Caixas de Esgoto Sanitário x Lajes & 54 \\
\hline Tubulação de Esgoto Sanitário x Lajes & 178 \\
\hline Conexões de Água Fria x Lajes & 31 \\
\hline Tubulação de Água Fria x Lajes & 64 \\
\hline Total & 391 \\
\hline
\end{tabular}

O maior número de interferências foi entre a tubulação de esgoto sanitário com as nervuras da laje (Figura 28), o que prova que o projeto hidrossanitário não levou em consideração o projeto estrutural. Caso a solução adotada para resolver o problema seja perfurar as nervuras da laje, deve-se tomar cuidado para não interferir na resistência da mesma e na segurança da edificação.

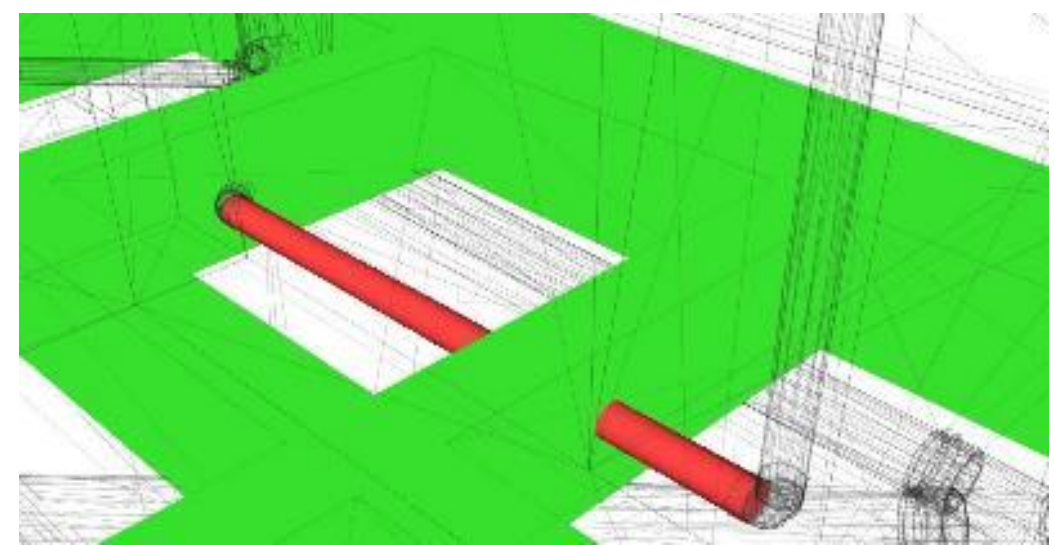

Figura 28: Interferência de tubulação de esgoto sanitário e nervuras da laje

Outro problema identificado foi o encontro entre a tubulação de água fria a e laje, isso se deu, principalmente, nos pontos de apoio da laje com as vigas (Figura 29). Portanto, deveria ter considerado a construção de shafts nas paredes para que as tubulações verticais ficassem livres das interferências com as lajes e vigas.

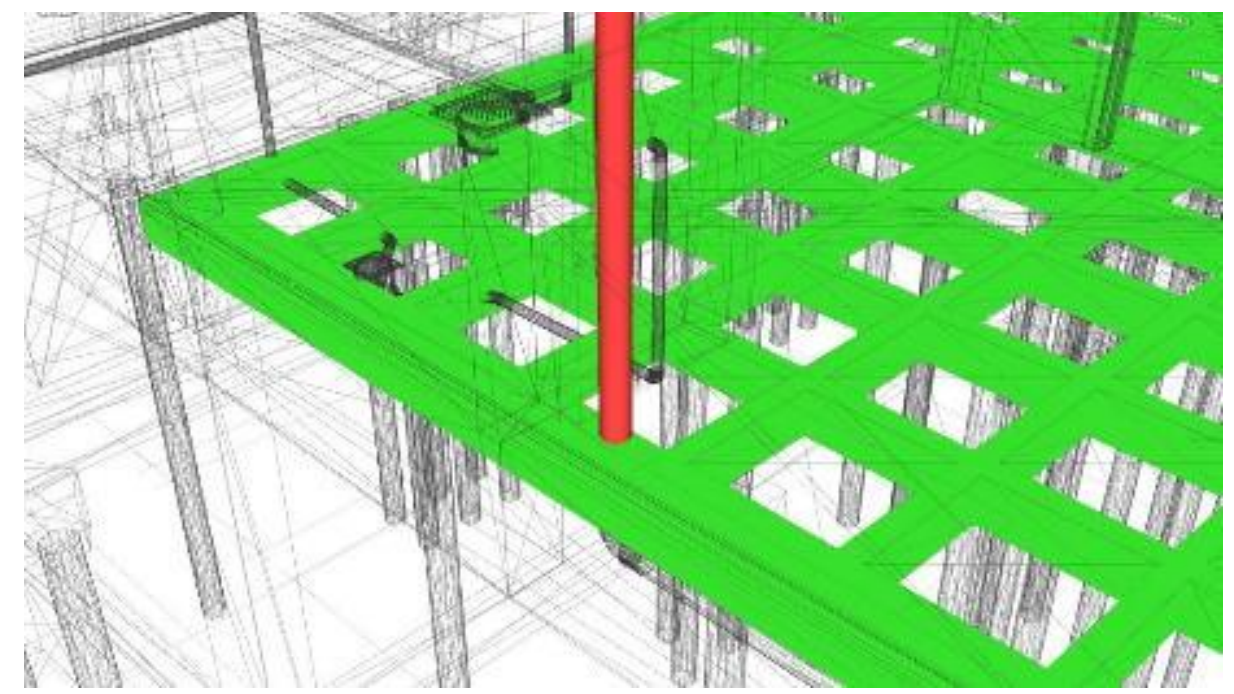

Figura 29: Interferência de tubulação de água fria e laje

As caixas sifonadas de esgoto sanitário também estavam mal posicionadas ocorrendo interferências que seriam simples de resolver na fase de projeto (Figura 30). Esses problemas poderiam ter sido evitados 
caso houvesse a compatibilização de projetos.

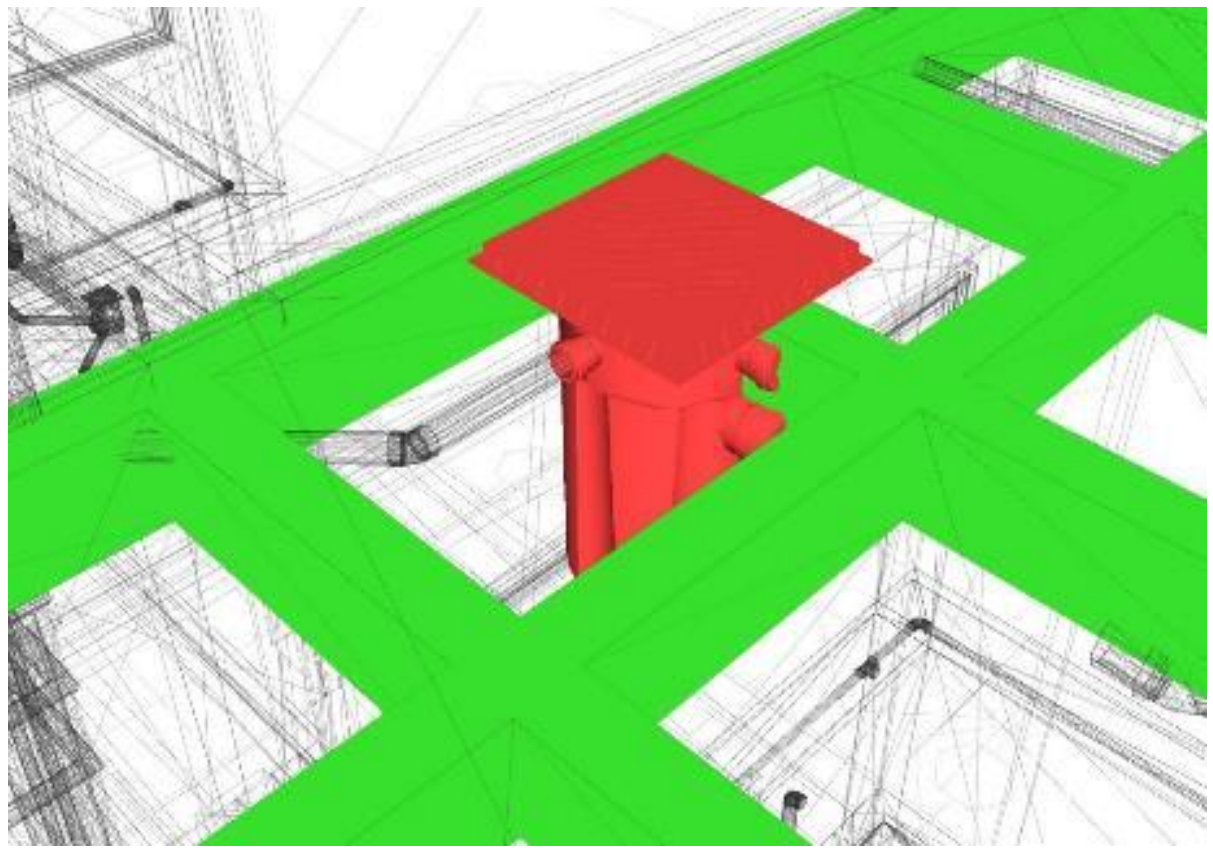

Figura 30: Interferência entre caixa sifonada de esgoto e nervuras da laje

\subsubsection{Interferências entre projeto arquitetônico (forro) e hidrossanitário}

Foram obtidas 148 (cento e quarenta e oito) interferências analisando os projetos de arquitetura e hidrossanitário, como pode ser visto na Tabela 13.

Tabela 13: Quantidade de interferências entre projeto arquitetônico (forro) e hidrossanitário

\begin{tabular}{|c|c|}
\hline TIPO & QUANTIDADE \\
\hline Projeto de Esgoto Sanitário x Projeto Arquitetura (Forro) & 120 \\
\hline Projeto de Água Fria x Projeto Arquitetura (Forro) & 28 \\
\hline Total & 148 \\
\hline
\end{tabular}

A Tabela 14 apresenta o número de interferências das subdivisões dos sistemas por seus componentes.

Tabela 14: Quantidade de interferências das conexões, caixas e tubulações com o forro

\begin{tabular}{c|c}
\hline \multicolumn{1}{c|}{ TIPO } & QUANTIDADE \\
\hline Conexões de Esgoto Sanitário x Forro & 72 \\
\hline Caixas de Esgoto Sanitário x Forro & 24 \\
\hline Tubulação de Esgoto Sanitário x Forro & 24 \\
\hline Tubulação de Água Fria x Forro & 28 \\
\hline Total & 148 \\
\hline
\end{tabular}

O maior número de problemas foi com as conexões, possivelmente, nos locais de mudança de direção em que as conexões se chocavam com as tabicas ou forro (Figura 31). 


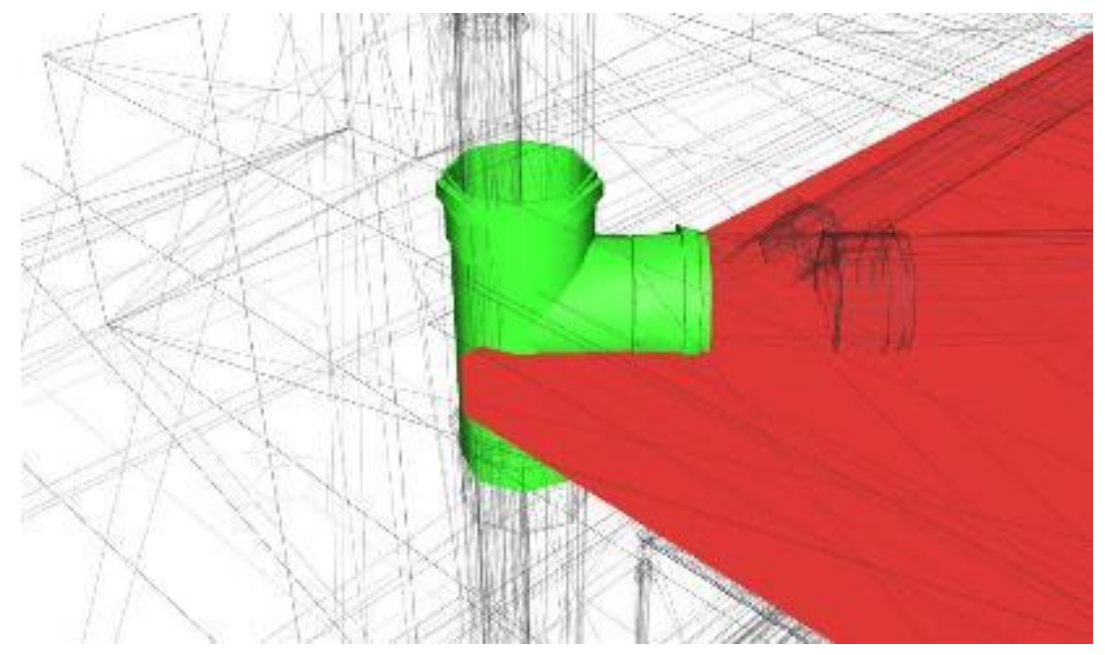

Figura 31: Interferência entre o forro e curva do sistema de esgoto sanitário

As caixas sifonadas, devido ao seu tamanho, já tendem a reduzir a altura do pé direito do ambiente do pavimento abaixo. Porém, ainda assim, houveram erros com as caixas e forros devido ao mal planejamento (Figura 32).

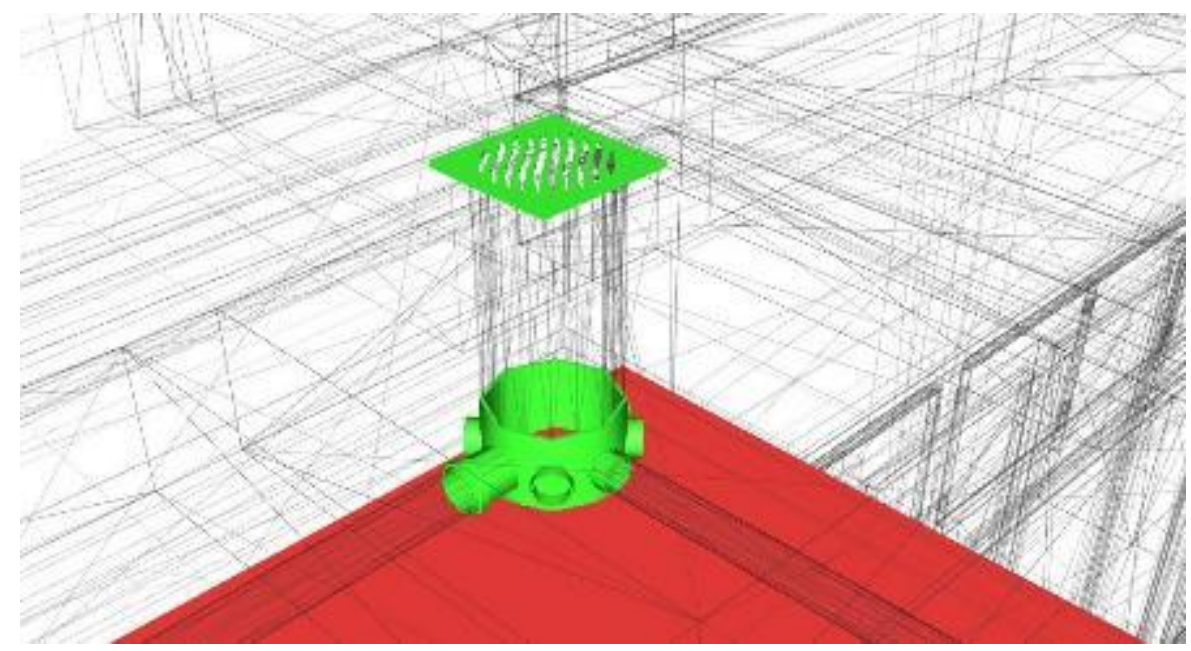

Figura 32: Interferência entre caixa sifonada e forro

\subsubsection{Interferências entre projeto hidrossanitário: tubulações de água fria e esgoto sanitário}

Foram obtidas 66 (sessenta e seis) interferências dentro do mesmo projeto, apenas analisando as tubulações de água fria e esgoto sanitário. Na Figura 33 pode ser observada a sobreposição das tubulações água fria (vermelha) com o tubo vertical de esgoto sanitário (verde).

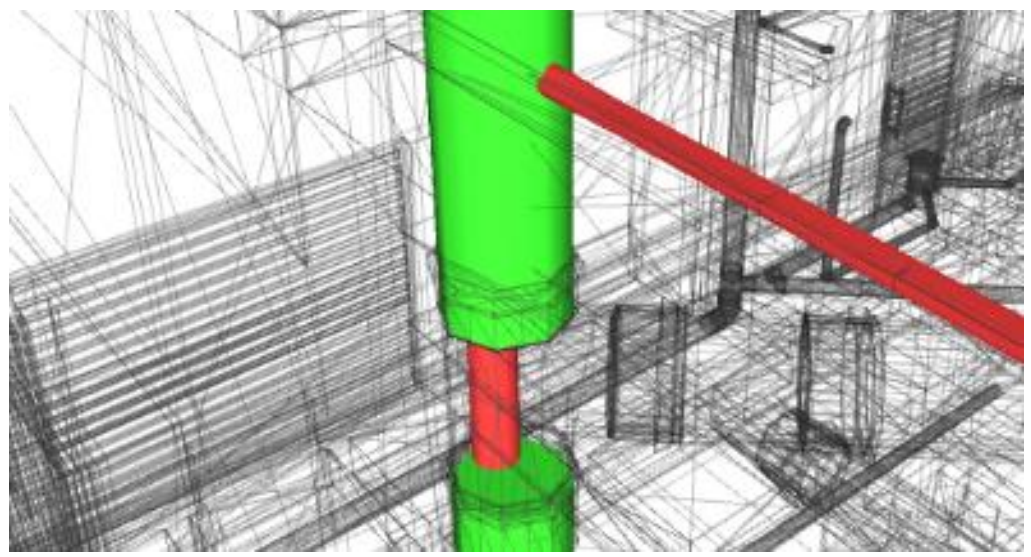

Figura 33: Interferência entre tubulações de água fria e esgoto sanitário

As interferências entre pilares e as tubulações e/ou conexões são problemas que fazem aumentar os 
custos da obra. Pois, há a necessidade de fazer modificações que irão acrescer a quantidade de material, o sistema hidrossanitário será modificado o que pode diminuir a performance do mesmo e, o tempo a mais de execução dos serviços, pode levar ao atraso das atividades.

Outro problema comum é a passagem de tubulação em viga. Neste caso é necessário fazer uma análise estrutural para a verificação da viabilidade do ocorrido. Mesmo diante da possibilidade de um problema deste acarretar em acidentes fatais, é comum, principalmente, em obras de pequeno porte, a perfuração de vigas sem o consentimento e respaldo de um responsável técnico qualificado.

Analisando todas as interferências e criando um cenário para classificá-las como as identificáveis apenas no momento da execução e as identificáveis analisando os projetos em pranchas, tem-se o resultado exposto na Tabela 15. Nota-se que mais da metade dos problemas poderiam ter sido solucionados verificando os projetos em prancha, este dado comprova a importância da figura de um gestor ou gerente de projetos.

Tabela 15: Simulação de um cenário da identificação das interferências em projeto ou em obra

\begin{tabular}{|c|c|c|c|}
\hline & EXECUÇÃO & PROJETO & TOTAL \\
\hline Fundação x Hidrossanitário & 0 & 2 & 2 \\
\hline Pilar x Hidrossanitário & 47 & 35 & 82 \\
\hline Viga x Hidrossanitário & 80 & 29 & 109 \\
\hline Laje x Hidrossanitário & 189 & 202 & 391 \\
\hline Forro x Hidrossanitário & 52 & 96 & 148 \\
\hline Água Fria x Esgoto Sanitário & 0 & 66 & 66 \\
\hline Total & 368 & 430 & 798 \\
\hline
\end{tabular}

\section{CONCLUSÕES}

O produto direto da modelagem dos projetos utilizando o BIM foi a criação de um modelo tridimensional da construção. Este modelo contém todas as informações relativas ao projeto, como as famílias de pisos e paredes a serem utilizadas na construção. Essa criação permitiu que fossem observados, mesmo que empiricamente, os benefícios da tecnologia no processo de projeto.

Durante o processo de modelagem foi observado a ocorrência de ganhos significativos no processo de projeto. Os ganhos se deram na criação de vistas concisas e com características fieis aos elementos modelados, além da atualização automática no posicionamento de elementos. Fato este que permite identificar futuros erros já na etapa de projeto.

Outro ganho se deu na possibilidade de extração de quantitativos. Uma vez que os elementos (de parede, por exemplo) foram modelados de modo a conter a maior quantidade de informações possíveis, estas puderam ser extraídas de maneira simplificada em qualquer etapa da modelagem.

A tridimensionalidade dos elementos permitiu uma visualização mais fácil e simplificada dos componentes das disciplinas modeladas (Arquitetura, Estrutura e Sistemas Prediais). Elementos que apresentavam baixo nível de detalhes puderam ser concebidos de forma a fornecerem melhor entendimento, mesmo aos leigos.

A modelagem em BIM permitiu ainda, a realização da análise de interferência entre os elementos do projeto, isso possibilita que problemas que possivelmente seriam detectados na execução já fossem solucionados na fase de projeto. Assim, seriam evitados gastos desnecessários com retrabalhos, ou seja, custo de mão-de-obra e materiais, e atrasos do cronograma da obra.

Com a análise das interferências obteve-se que 53,88\% dos problemas poderiam ter sido identificados na fase de projeto. Este percentual é expressivo, pois o transtorno que uma interferência gera na obra poderá interferir em outras atividades da mesma, ocorrendo atrasos e o não cumprimento de prazos, além do gasto a mais não previsto em orçamento inicial.

É visível um horizonte de aplicação do BIM mesmo para obras com porte não tão grande, considerando sua vasta aplicação em grandes empreendimentos. A visualização holística que a plataforma prevê permite uma maior integração das equipes envolvidas, fato este que promove a resolução mais rápida de problemas ainda na fase de projeto. 


\section{AGRADECIMENTOS}

Aos engenheiros e arquitetas autores dos projetos e responsáveis pela execução, pela presteza em cedê-los e esclarecer os eventuais questionamentos.

\section{BIBLIOGRAFIA}

[1] CHIEN, K. F., WU, Z. H., HUANG, S. C., "Identifying and assessing critical risk factors for BIM projects: Empirical study", Automation Construction, pp. 1-15, Abril 2014.

[2] CAMPESTRINI, T. F., GARRIDO, M. C., MENDES JÚNIOR, R., et al., Entendendo BIM: Uma visão do projeto de construção sob o foco da informação, 1 ed., Curitiba, Universidade Federal do Paraná, 2015.

[3] OH, M., LEE, J., HONG, S. W. et al. Integrated system for BIM-based collaborative design. Automation in Construction, v. 58, pp. 196 - 206, 2015.

[4] LINDEROTH, H. C. J. Understanding adoption and use of BIM as the creation of actor networks. Automation in Construction, n. 19, pp. 66-72, 2010.

[5] WON, J., CHENG, J. C. P., LEE, G. "Quantification of construction waste prevented by BIM-based design validation: Case studies in South Korea", Waste Management, n. 49, pp. 170-180, 2016.

[6] MARIANI, M. A., BIANCHI, P. C., WRIGHT, R. et al. "O impacto do BIM: estudo de caso em edifício residencial", In: anais do XVI Encontro Nacional de Tecnologia do Ambiente Construído, pp. 4889 - 4909, Porto Alegre, Set. 2016.

[7] LI, J., HOU, L., WANG, X., WANG, J. et al. "A Project-based Quantification of BIM Benefits", International Journal of Advanced Robotic Systems, pp. 1-13, agosto 2014.

[8] EASTMAN, C., TELCHOLZ, P., SACKS, R., et al. Manual de BIM: um guia para modelagem da informação da construção para arquitetos, engenheiros gerentes, construtores e incorporadores. 1 ed., Porto Alegre, Bookman, 2014.

[9] GIL, A. C., Como Elaborar Projetos de Pesquisa, 4 ed., São Paulo, ATLAS S.A., 2002.

[10] MELO, M. F. A. Projeto Arquitetônico - Edifício Residencial Multifamiliar. Catalão: $\mathrm{m}^{2}$ - Arquitetura, Urbanismo e Paisagismo., 5 p., 2014. Acessado em julho 2016.

[11] CUNHA, J. C. Projeto de Estrutura em Concreto Armado - Edifício Residencial Multifamiliar. Catalão: Jose Carlos Cunha: Engenharia de Estruturas, 2014. Projeto cedido pelos autores em julho 2016.

[12] ROCHA, J. R. E. Projeto Hidrossanitário - Edifício Resid. Multifamiliar. Catalão, Catenge, 2014. Projeto cedido pelos autores em julho 2016.

[13] BRAGA, C. Projeto de detalhamento e paginação - Edifício Residencial Multifamiliar. Catalão: Camila Braga Arquitetura, 2015. Projeto cedido pelos autores em julho 2016. 